\title{
Factors predicting citizens' risk tolerance regarding earthquakes
}

\author{
By
}

Liv Henrich

A thesis submitted to Victoria University of Wellington

in fulfilment of the requirements for the degree of

Master of Science in Psychology

Victoria University of Wellington

2014 


\section{Acknowledgements}

I would like to acknowledge the people who have contributed to the completion of my thesis. First and foremost I would like to thank Professor John McClure for his excellent supervision, for sharing this knowledge and expertise in the field, for his mental support and fatherly guidance throughout this year. I feel very honoured that and factor analysis expert Associate Professor Frank Walkey contributed so heavily to the completion of this thesis and to my own understanding in factor analysis. I would also like to thank Johanna, Mat, Meredith and Lauren for helping with the data collection, without which this thesis would not exist. Finally, I want to thank my partner Mat for his understanding and support, my parents, Uschi and Dirk and my siblings, Julia, Lukas and Claas who have supported and encouraged me along the way to pursue my post graduate study. 


\begin{abstract}
People tolerate different levels of risk from different hazards in their day-to-day life. Perceptions of risks and the amount of risk mitigation people desire for different hazards vary. Previous research shows that the psychometric properties of different hazards predict the level of risk people tolerate for various hazards, but not for earthquakes. Risk tolerance is likely to also be affected by factors other than the psychometric properties of hazards. This research tested how earthquakes score on psychometric risk properties compared to five other hazards, and aimed to replicate previous research on the risk factors predicting risk tolerance. Secondly, the research aimed to test if other factors, namely framing effects, risk perception and fatalistic thinking predict risk tolerance for earthquakes. In Study 1, participants from Wellington, New Zealand $(\mathrm{N}=139)$ rated six different hazards (nuclear power, smoking, alcohol, driving, flying and earthquakes) on several risk characteristics and measures of risk tolerance. The results showed that the different hazards were perceived differently in terms of risk tolerance and that participants thought different risk mitigation actions were appropriate for the six hazards. Factor analysis showed that factors derived from risk characteristics did not predict risk tolerance. Study $2(\mathrm{~N}=173)$ assessed the effects of framing messages, risk perception and fatalism on risk tolerance (judgments about the firmness of the legislation; willingness to pay tax) and judgments about who should pay. The frames had an effect on participants' concern about the risk, but did not affect the other measures. Generally participants thought that the Government should pay for strengthening buildings, however, those participants who perceived damage as preventable (fatalism measure) thought that private owners should pay for strengthening.
\end{abstract}




\section{Contents}

Acknowledgements ................................................................................................ 2

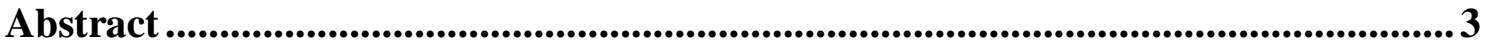

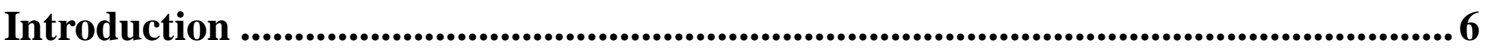

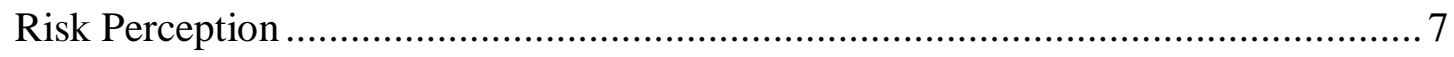

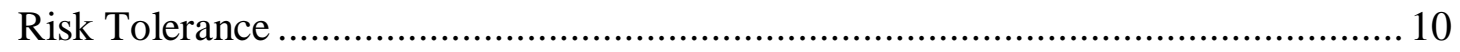

Psychometric Approach to Understanding Risk Tolerance...................................... 11

Other Factors that may influence Risk Tolerance for Earthquakes ......................... 13

Risk Tolerance and Natural Disasters ................................................................. 19

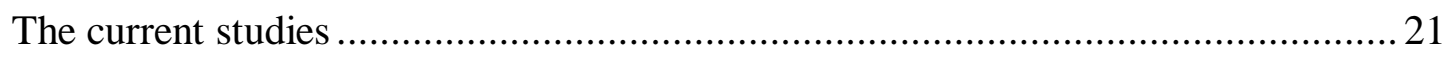

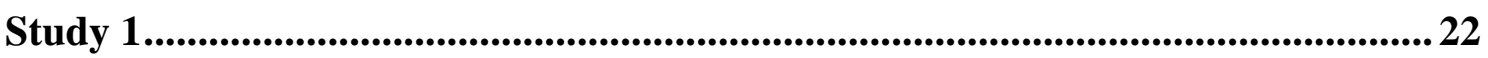

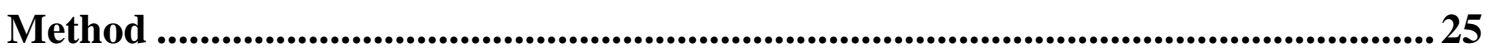

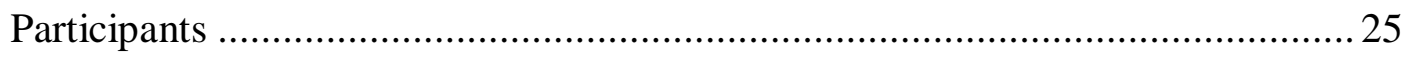

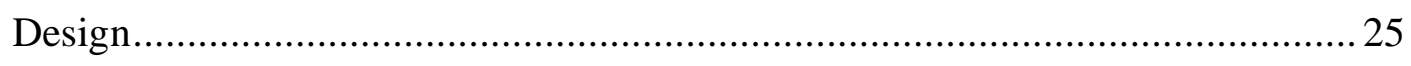

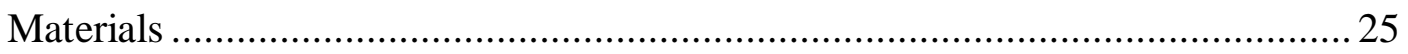

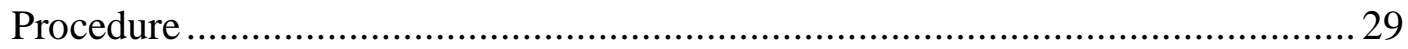

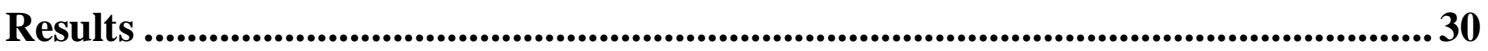

Risk Characteristics for the different Hazards ............................................. 30

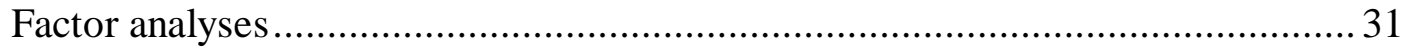

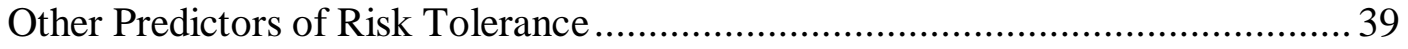

Comparing different hazards on risk tolerance measures................................... 39

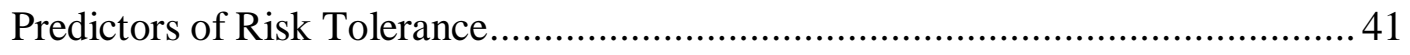

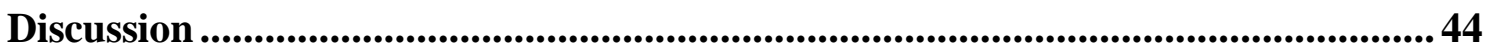

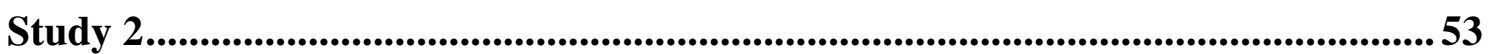

Method Error! Bookmark not defined. 


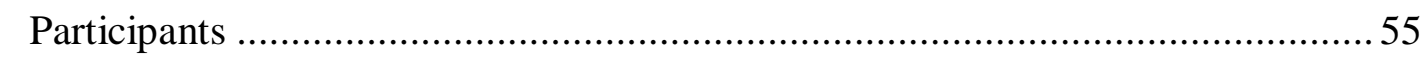

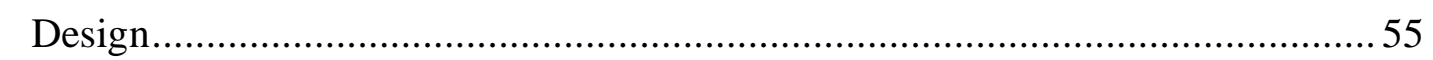

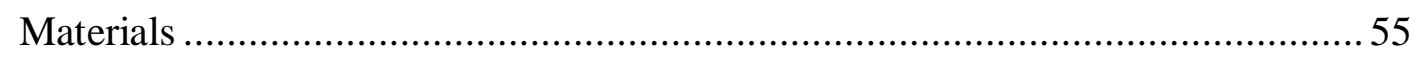

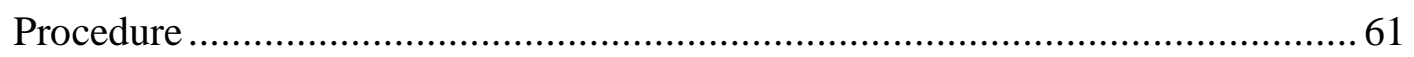

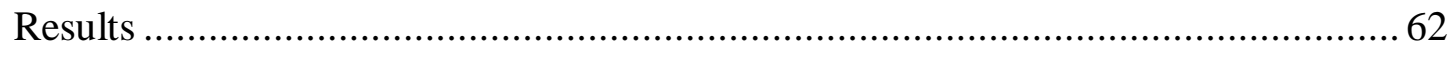

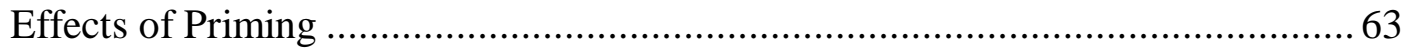

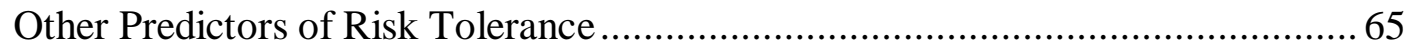

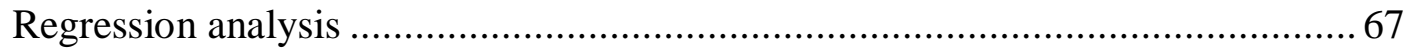

Discussion................................................................... Error! Bookmark not defined.

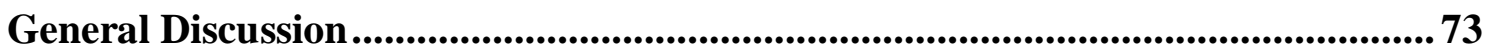

Risk Perception and Risk Tolerance of different Hazards (Study 1) ....................... 73

Other Potential Influences on Risk Tolerance (Study 2)....................................... 74

Differences in Risk Tolerance and Who Should Pay.............................................. 75

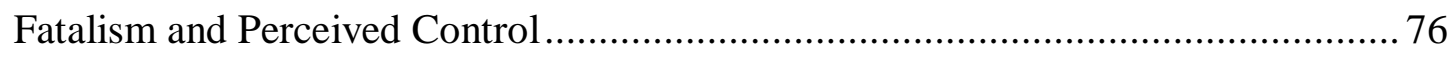

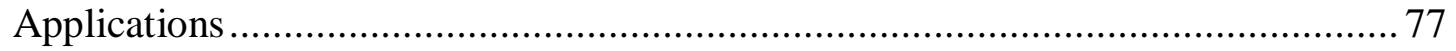

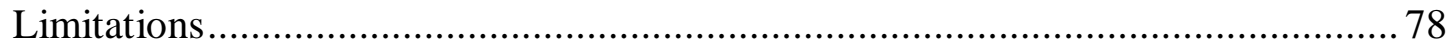

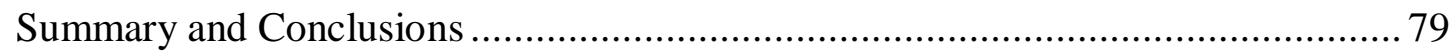

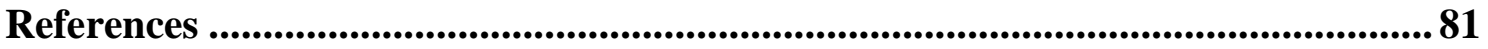

Appendix A: Questionnaires Study 1 ...........................................................................8 86

Appendix B: Priming Messages and Questionnaires Study 2 ...................................88 


\section{Introduction}

Every community faces a number of hazards on a daily basis. These hazards can range from the effects of pesticides in foods, driving on dangerous roads to the risks of damage from major earthquakes in many areas of the world. It is useful to know which hazards, in the eye of the citizen, are safe enough and which ones need to be addressed by risk mitigation strategies. For policy makers, it is a challenge to know which hazards to focus on in terms of risk reduction, especially when funding for risk mitigation is limited (Slovic, 1987). Because funding for risk reduction is often divided between the Government and the public (Hubbard, 2013), risk mitigation policies should, at least in part, reflect citizens' attitudes towards these risks.

Should we aim to reduce the risk of lung cancer by encouraging people to quit smoking? Not everyone in the community smokes or is prepared to pay for mitigating the risks of other people smoking. Should most of the available risk mitigation funds go towards making roads safer, or should we focus on strengthening earthquake prone public buildings first? How should the costs of these actions be divided? Questions like the latter in relation to mitigating risks from earthquakes have frequently been raised in New Zealand, especially since the Christchurch earthquakes in 2010 and 2011 and indicate that this issue is a major concern for New Zealanders (Hubbard, 2013). In order to make insightful and effective decisions, policy makers need to understand how the public perceives risks and what implications risk communications have for people's acceptance of various levels of risk for different hazards (Slovic, Fischhoff \& Lichtenstein, 1984).

In New Zealand, since the 2010/2011 Christchurch earthquakes, which killed 185 people (New Zealand Police, Official fatality list) and caused $\$ 40$ billion worth of 
damage, there has been a major debate about whether earthquake prone public buildings across the country need to be strengthened and in what timeframe (Hubbard, 2013). Because the cost of this strengthening work has been estimated to be about $\$ 1.7$ billion, part of the debate is based on the question of whether the cost of strengthening buildings outweighs the benefits of preparing for low frequency events like major earthquakes across the whole country. Further informing the debate is new proposed legislation that would require all earthquake prone buildings to be assessed within a five year span and strengthened to a minimum of $34 \%$ of the current building code within 10 (and in some cases 20) years. This Building Amendment Bill is a response to the Canterbury earthquakes and aims at providing a minimal national building standard for all commercial buildings (Parliamentary Counsel Office). Some regional authorities have, over the past decade, enacted their own methods of identifying at risk buildings and enforcing modifications or demolitions and the new legislation would standardise such efforts nationwide (Wellington City Council, Earthquake Prone Buildings).

In order to make more informed decisions about strengthening earthquake prone public buildings in New Zealand, it is useful to understand more about the public's perception of the risk, how much of that risk they are willing to tolerate and which factors influence these risk judgments.

\section{Risk Perception}

Slovic (1987) describes risk perceptions as 'intuitive risk judgments' and opposes the idea that risk perceptions are solely based on probabilities. He argues that in understanding risks and the probabilistic values associated with them, people intuitively use heuristics to make sense of a complicated reality. Using heuristics does not always lead to an accurate understanding of the risk and can contribute to perceptual biases. 
Media portrayals of hazards and their outcomes inform these perceptual biases (Slovic, 1987).

Perceptual Heuristics. One of these heuristics, the availability heuristic, first studied by Tversky and Kahneman (1973), describes the effect that the ease of retrieving information from memory has on judgments about the frequency of events. Thus an event is judged as occurring more frequently when it can easily be recalled or imagined. Personal experience, vividness, and media coverage influence the ease by which information is recalled. This heuristic, as mentioned above, leads to inaccuracies in risk perception (Tversky \& Kahneman, 1974) and also affects likelihood judgments of hazards. For example, people often over-estimate the likelihood of certain rare events, like shark attacks, because the events are covered extensively in the news media (Slovic, 1987). Another example concerns the effects of news media reports on disasters and technological mishaps. As a result, many people in the industrialised world estimate that risks have increased and are increasing over time even though most technologies have become more regulated, more advanced and less prone to mishaps over time (Slovic, 1987).

Effects of Framing on Earthquake Risk Perception. Another factor influencing risk judgments is the way messages are framed. In a study by McNeil, Pauker, Sox and Tversky (1982), participants were told to imagine they had lung cancer and had two medical treatment options (surgery or radiation). Some participants were given the cumulative chances of the number of people who survive for each treatment whereas other participants were given the cumulative probabilities of people dying after receiving either treatment option. For example, some participants were told that $68 \%$ of those who have surgery survived one year after the surgery, while other participants 
were told that $32 \%$ of those who receive the surgery would have died after one year. Although these outcomes are identical, the framing of the options significantly affected which option participants chose, depending on whether they were told the chances of surviving or dying. Thus the percentage of people choosing radiation over surgery was reduced from $44 \%$ to $18 \%$ when they were presented with the information stating the likelihood of dying due to radiation. McNeil et al.'s study also relates to the perception of risk and the severity of outcomes. Several studies have examined that if the severity of an outcome is high, then people tend to see the likelihood of the outcome as higher than it actually is (Bruin de Bruin, Fischhoff, \& Halpern-Felsher, 2000; Joslyn, \& Nichols, 2009; Joslyn. Nadav-Greenberg, Taing, \& Nichols, 2009; Patt, \& Dessai, 2005; Windschitl, \& Weber, 1999).

Similarly, the framing of earthquake risk could influence people's decisions about accepting planned policies and legislation. The same earthquake risk can be described in different ways that are logically identical yet have different effects on risk judgments. For example, people judge the risk of an earthquake as higher when presented with the sentence: "There is a $10 \%$ chance in 50 years that 1600 people will die [due to an earthquake]" than the sentence "An earthquake that occurs every 500 years kills 1600 people", even though they describe exactly the same risk (Crozier, McClure, Vercoe \& Wilson, 2006; Henrich, 2013). If risk perceptions are malleable and can be influenced by judgemental biases and framing, then the amount of risk (from any given hazard) which people tolerate in their lives may also be affected by these changes in risk perception.

McClure, White and Sibley (2009) examined whether the effects of framing extend to judgments about the importance of preparing for earthquakes. Four groups 
read statements in which the action of preparing for earthquakes and the outcomes were described. They distinguished between the valence framings of the action and the valence framing of the outcome. For example, a positive action paired with a positive outcome read "If you are well prepared for a major earthquake you are likely to have a greater chance of surviving in the event unharmed", whereas a negative action frame paired with a negative outcome read "If you are poorly prepared for a major earthquake you are likely to have a greater chance of experiencing harm in the event". The results showed that the negative outcome frame affected attitudes towards earthquake preparation and increased judgments of risk, intentions to prepare and the importance of earthquake preparation.

\section{Risk Tolerance}

The way in which people perceive risk is likely to influence what level of risk they are willing to accept in their lives and how important it is for them to prepare. Risk tolerance describes people's level of risk acceptance on a day-to-day basis. An acceptable risk level is a level at which the hazard is judged to be safe enough, or unlikely enough. People perceive hazards, technologies and activities at this level as requiring no further risk mitigation action. Other hazards are perceived as too risky, and thus people have a lower risk tolerance for them. Such hazards are perceived as requiring some form of action or regulation in order to reach an acceptable risk level (Slovic, Fischhoff \& Lichtenstein, 1985).

The underlying question that policy makers try to answer when deciding on new legislation to reduce risk, is 'How safe is safe enough?'. In practical settings, this can take the form of questions like 'Should schools with asbestos ceilings be closed?' or 'Should there be additional containment shells around nuclear power plants?' 
(Fischhoff, Slovic, \& Lichtenstein, 1979) or 'Should earthquake prone buildings be demolished or strengthened in a set time frame?'. Public debates like these can indicate that the public's risk tolerance of the hazard is lower than its current level of regulation.

Levels of risk tolerance can be measured by assessing people's willingness to pay for the mitigation action to adjust a certain risk. For example, Botzen and van den Bergh (2012) asked people to indicate how much they would be willing to pay for an all-encompassing flood insurance, to measure people's level of risk tolerance for floods in the Netherlands. They found that willingness to pay for insurance increases with heightened perception of risk.

\section{Psychometric Approach to Understanding Risk Tolerance}

The psychometric approach has been used to establish why people are more tolerant of some hazards than of others and why the demand for regulation and safety standards is higher for some hazards than others (Slovic, 1987). This approach assesses the psychometric properties of different hazards, technologies and activities and uses these to predict how people perceive the associated risks and how much mitigation they desire for those risks (Slovic et al., 1984). A taxonomy based on risk characteristics can help decision makers understand why people tend to be extremely averse to some risks and demand strong regulation for them whereas they seem indifferent to others (Slovic et al., 1984).

Early studies of risk tolerance claimed that risk tolerance would be influenced by the number of people killed or injured and the amount of property damaged, and whether it is a risk people take voluntarily (Slovic, 1987). Voluntary risks are those activities that people engage in voluntarily (e.g., skiing), whereas involuntary risks (e.g., food preservatives) are those that are not directly under personal control. Voluntary 
risks have a higher threshold for risk tolerance because people often perceive the benefits to the individual as disproportionately higher than the risks associated with the activity (Slovic, 1985). More recently, researchers have considered many other factors that influence people's risk perception and as a result their risk tolerance.

Characteristics such as 'Catastrophic potential', 'knowledge about the risk' or 'control over the outcomes' have been added. The risk characteristics commonly assessed by Slovic and colleagues (e.g., Slovic et al., 1985) are:

1. Whether the risk is one that people face voluntarily

2. If the effects of the risk are immediate or delayed

3. The extent to which the risk is known to those exposed

4. The extent to which the risk is known to science

5. How controllable the risk is

6. How new the risk is

7. Whether the risk is catastrophic in that it kills many people at once

8. Whether it is a risk that people dread at a level of gut reaction

9. How severe the consequences are (i.e. how likely the consequence is to be fatal)

Factor-analytic studies have found that across a wide range of different hazards, many characteristics cluster together and form two major factors (Slovic, 1985). One factor which many hazards load on was termed 'Unknown Risk'. This factor suggests that people are generally more afraid of hazards of which the outcomes are mainly unknown and is defined by high scores on being involuntary, unknown, new, and delayed in their outcomes. A good example representing high scores on this factor are chemical technologies. The second factor, 'Dread', measures the amount of dread people have for the different hazards on a daily basis. This factor represents high scores 
on the characteristics "perceived lack of control", "dread", "catastrophic potential", "certain to be fatal" and "inequitable distribution of risks and benefits". Thus "dread" was a characteristic, and when it grouped with the other 4 characteristics to form a factor, this factor was also called 'Dread'. Nuclear power and the associated outcomes of a mishap provide an example of a hazard that scores high on this factor (Slovic, 1987).

Slovic (1987) found that people desired more mitigation in form of regulation for hazards that score high on both the Unknown Risk factor and the Dread factor. Again, nuclear power is an example of this observation. According to this research, by determining where a hazard scores on the factor structure, it is possible to predict how tolerant people will be of the risk and how much regulation they are likely to demand for it. Slovic's research on factors as predictors of risk tolerance focussed on activities or technologies, like skiing or different chemicals, and not natural hazards. Thus more research is needed to understand where natural hazards like earthquakes score on these characteristics and the derived factors.

\section{Other Factors that may influence Risk Tolerance for Earthquakes}

Risk characteristics are not the only factor that influences risk tolerance. Other factors include fatalism, cost-benefit considerations and the way risk is defined.

Fatalism. Fatalistic thinking refers to people's tendency to think that the outcome of an event is outside of human control (McClure, Allen \& Walkey, 2001). Fatalism has been found to influence people's risk perception. Earthquakes present a case in which the event itself is uncontrollable, however outcomes in earthquakes such as damage and fatalities are partially controllable through building codes and personal preparation. Important for understanding the basis of fatalistic thinking are attributions. 
People who are fatalistic are more likely to attribute earthquake damage more to than controllable factors like building design. This implies that people with fatalistic beliefs about earthquake damage doubt that structural mitigation actions will save them from damage and harm (McClure et al., 2001). Fatalism is one factor which can influence people's perception of the value of preparation and determine how much mitigation people desire for earthquake risk.

Previous research showed that levels of fatalism can be manipulated by framing messages of news media reports. McClure, Sutton and Sibley (2007) found that people judge the preventability of damage following earthquakes differently when they are presented with two different types of news media messages. Rate-based information emphasises the resilience of well-designed buildings and indicates that damage occurs at a higher rate in old buildings with poor structural design. On the other hand, instancebased messages commonly found in news media focus on instances in which newly built houses or motorways were severely damaged. Such instance-based information which focuses on damage to new buildings, without presenting the rate at which old buildings are damaged in comparison, suggests that there is little that stricter building codes can do to prevent damage and increases fatalistic beliefs. The results also showed that people who read instance-based messages are more likely to attribute damage to the force of the earthquake than to the design of the building. Thus media messages influence levels of fatalistic thinking in terms of the value of preparation actions such as strengthening buildings.

In a related study, Cowan, McClure and Wilson (2002) tested whether newspaper articles that appeared either one day or one year after major earthquakes affected people's fatalism and their attributions for earthquake damage. Articles 
published the day after the earthquake reported widespread, indiscriminate damage to many houses and gave no comparative information on the percentage of all houses damaged. Articles written one year after the earthquake, however, compared specific damage to some houses to the percentage of undamaged buildings of higher building standards. Their results show that people reading the 'day-after' reports were more likely to attribute the damage to the magnitude of the earthquake whereas people who read the 'one year after' reports were more likely to attribute damage to building design.

Thus attributions for earthquake damage have been shown to be affected by the messages that people were presented with. Attributions to controllable causes such as building design are a necessary basis for taking preparation actions. Attributions also affected judgments of other factors such as cost, which influences mitigation behaviour (McClure et al., 2001).

Cost-Benefit considerations. Public perceptions about risks and benefits influence the acceptance of new technologies, medications or safety measures and should be considered during the policy decision making process (Fischhoff et al., 1979). Inherent in the public's task of deciding on advances that will make communities safer is a societal dilemma: all attempts to reduce risk usually entail a reduction in the benefit that is associated with the risk. For example, if the risks of certain vaccinations are perceived as too large in comparison to the benefits, regulations might be changed so that parents can choose not to have their children vaccinated. This may in turn increase the incidence of the disease that the vaccination was meant to prevent. As a result, the benefits of the vaccination will be reduced as well as the risks (Baron, 2000). The harm from heavy alcohol consumption can be reduced by increasing the price for alcohol, but this also reduces the benefits for moderate and responsible drinkers (Wannan, 2014). 
The same logic can be applied to natural hazards and earthquakes in particular. The risk that an earthquake occurs cannot be reduced through regulation, but the outcomes of earthquakes, such as death and damage, can be greatly reduced by strengthening buildings to resist the forces released during earthquakes. This form of risk reduction through strengthening buildings comes at a large cost to the ratepayer or the building owner. On the other hand, if citizens accept the risk of a major earthquake occurring without having buildings strengthened, then the resources that would be used on strengthening projects could be used for other important matters, such as increasing the funds for education or making roads safer. Given the infrequent nature of major earthquakes, some people find that the costs of strengthening buildings outweigh the benefits (Moran, 2001).

Conservative and broad definitions of risk. The view that the costs of strengthening buildings outweigh the benefits has been expressed in the New Zealand media for some time. Some people argue that the prospect to strengthening all earthquake prone buildings in New Zealand following the events in Christchurch in 2011 is an over-reaction (Clark, 2012). This view is often expressed in newspaper articles which describe risk from earthquakes as negligibly small.

Some experts base risk perception on conservative measure of risk, such as annual fatality rate (Slovic, 1984). The argument against stricter building standards is that the likelihood of being killed due to an earthquake per year is negligibly small compared to other causes of death, like car crashes. Research shows that other experts and lay people on the other hand base their risk perception and the desire to mitigate future risk on broader criteria which take into account the unstated or omitted costs of damage, such as emotional loss or trauma (Slovic \& Weber, 2002). Much of the public 
debate about earthquake risk revolves around the definition of cost and whether one takes into account costs that are difficult to measure, like trauma from losing one's home and living in a garage, on-going disputes with insurance companies, or the longterm effects of the experience of a major earthquake on children in the area (Brower, 2013). Broadly speaking, the conservative measure defines the risk as the annual fatality rate and does not include so-called 'ripple effects' such as lost business opportunities, whereas the broader definition of risk includes those longer term 'ripple effects' (Slovic \& Weber, 2002).

When faced with risks, people have a tendency to react in one of two ways in order to reduce their anxiety about the risk (Slovic, 2000). The first strategy assumes that preparation will mitigate the risk. The second strategy is to convince oneself that the likelihood of the risk occurring is so small that it can be neglected. Both strategies result in a reduction of anxiety and both of them either use a conservative measure of risk or a broader definition of cost. Those people who see earthquake risks in New Zealand in terms of the likelihood of being killed per year, argue that the likelihood of an earthquake is so small it does not need to be dealt with (Moran, 2001). Others who endow the preparation strategy to lower their anxiety, on the other hand, argue that current attempts to make buildings safer is an under-reaction (Brower, 2013).

Media messages reflecting different cost-benefit considerations. Many of the messages about costs and benefits are communicated to the public through newspaper articles. Often these either reflect the view that the new earthquake legislation is an over-reaction or that it is an under-reaction, in that not enough is done to mitigate risk.

As an example of over-reaction messages, Peter Johnstone, an earthquake building design engineer, claimed in a 2001 newspaper article in the Dominon Post that 
citizens of Wellington should be less concerned about earthquakes because the actual number of fatalities due to earthquakes over the past 80 years was negligibly small (fewer than 300), whereas New Zealand's road toll was about 500 per year, which would render about 40,000 deaths over 80 years. Even after the Christchurch earthquakes in which 185 people died, this argument is put forward (Clark, 2012). The message here is that the demand for building strengthening for all earthquake prone buildings across New Zealand is an over-reaction driven by emotional reactions after the Christchurch earthquakes, not by statistical predictions.

An example of under-reaction messages was quoted by Ann Brower, a senior lecturer in public policy at Lincoln University, who was the only survivor when an unreinforced masonry building in Christchurch collapsed onto the bus she was travelling on. Having experienced such a dramatic and for the other passengers fatal situation, her argument proposes the opposite point of view to the over-reaction message. She argues that it is wrong to not strengthen public earthquake-prone buildings in New Zealand immediately, because all citizens of an earthquake-prone country like New Zealand bear the risk of dying in a public space during a major earthquake (Brower, 2013).

In addition, whereas some say it is too expensive to reinforce all buildings, this viewpoint argues that the Government's cost-benefit analysis should, instead of estimating the cost of strengthening buildings, consider the cost of not reinforcing buildings. Those costs include the cost of caring for all those that are injured or disabled or those that are traumatised. In Christchurch in 2011 after the second major earthquake, more than 6000 people were injured, 25 permanently disabled and 185 who were killed (Brower, 2013). Thus her main argument is that the government has not taken these 
costs into account when proposing that earthquake prone buildings in New Zealand will have up to 20 years to be brought up to $34 \%$ of current code.

A similar view focusses on the financial comparisons between the cost of strengthening buildings in advance and the cost of rebuilding cities after an event (Dominion Post, August, 2013). The author's main argument is that compared to the cost of rebuilding a city like Christchurch, which is estimated at $\$ N Z 40$ billion, the cost of strengthening all earthquake prone buildings across New Zealand, estimated at \$NZ 1.7 billion, is an acceptable price to pay for safety. The author points to the cost of missed business opportunity and tourism, which should be included in the costs and benefits of strengthening earthquake prone buildings.

The difference between the over-reaction and the under-reaction viewpoints is based on the different ways of presenting statistical likelihoods but also on the definition and criteria of cost. The present research assesses the effects the two types of media messages have on people's risk perception and their judgments of the costs and benefits of strengthening earthquake prone buildings (Study 2).

\section{Risk Tolerance and Natural Disasters}

Few studies have examined the effects of framing of probabilities and comparative risk on risk perception and risk tolerance for natural disasters, which are usually characterised by low frequency and high impacts. McClure, Sibley and Rose (2013) examined why people tend to insure for high frequency - low impact events more readily than for low frequency - high impact events. One argument is that the cost of insuring for low frequency - high impact events is too high. They presented participants with different frequencies (recurrence rates of $1,4,16,64$ years) for the same hazard, but held the cost for insurance constant across all 4 frequency rates. They 
found that even with the insurance cost held constant, people were more likely to purchase insurance for high frequency events with recurrence rates of 1 or 4 years, than for low frequency events with recurrence rates of 16 or 64 years. Thus the framing of the frequency of the event may affect risk tolerance more than cost.

Botzen and Van den Bergh (2012) and Botzen, Van den Bergh and Aerts (2008) examined risk tolerance (measured as willingness to pay for insurance) for the low probability, high impact event of river flooding in the Netherlands, based on the assumption that probabilities are increasing due to climate change. They tried to account for the fact that people generally have difficulty understanding probabilities of events, especially if probabilities change over time (Hammit and Graham, 1999) and that information on risks and probabilities can influence knowledge of the risks acquired through experience.

Botzen and colleagues gave half of the participants risk ladders to communicate the risk of flooding and the changes in probability of flooding due to climate change. A risk ladder expresses the yearly probability of an event (in this case flooding) in relation to other risks which are more commonly known to participants, such as car theft or traffic casualties. Using arrows, the risk ladders also indicate how much the risk of flooding is likely to rise due to climate change. The other half of the participants were simply informed about the flood risk in a statement without using any visual aids. Participants indicated whether they would purchase flood insurance, if this was available and if they said yes, how much they were willing to pay in insurance per month.

The results showed that the higher people's perception of the flood risk was, the higher their demand for insurance. Participants who were told that climate change was 
increasing the risk of flooding had a $21 \%$ higher Willingness to Pay (WTP) than people who were not shown the information on climate change. WTP was also higher for people who thought that the area they lived in was at risk, whereas for people who thought their flood risk was lower than the national average, WTP was $25 \%$ lower. For those who expected no damage at all, WTP was $41 \%$ lower. People who perceived flood risk as outside of their control also had a lower WTP. When the risk and changes in likelihood were communicated using risk ladders, respondents were more sensitive to those changes in probability of flooding which influenced their WTP. Thus the way in which risk is communicated affected risk tolerance for flood risk.

\section{The current studies}

The current research has several aims. Study 1 assessed earthquakes in comparison to other hazards on psychometric dimensions and tests if the factor structure seen in Slovic's work can be found with the six hazards. Knowing the factor structure and where earthquakes score on this taxonomy could assist policy makers to assess how likely it is that lay people desire stronger legislation and expect Government action for strengthening earthquake prone buildings in New Zealand.

Study 2 aimed to test whether frames presenting the over and under-reaction messages influence earthquake risk perception, risk tolerance and the 'who should pay' question. It also tested whether risk perception and fatalism related to risk tolerance and judgments about who should pay.

This research thus extends the research on psychometric properties (Slovic, 1987) and adds to it by focussing specifically on earthquakes as a natural disaster. It also extends the research on framing to risk tolerance of earthquakes. 


\section{Study 1}

Study 1 has three goals. First, it examined the psychometric properties of six different hazards: Living in an area prone to strong earthquakes, smoking, heavy alcohol consumption, driving motor vehicles, flying (commercial) and nuclear power. These hazards, except for earthquakes, were chosen from the list of 30 hazards, technologies and activities presented by Slovic (1987), because they represent hazards which most people in New Zealand (Wellington) were likely to be familiar with. This was important because the aim of the study was to compare earthquakes with other hazards that the average citizen is likely to be familiar with.

Participants were likely to be familiar with these hazards for the following reasons. The Wellington area is in close proximity to five fault lines. Smoking is a common activity and its negative health outcomes are currently addressed by the Government by increasing tobacco tax (Wannan, 2014). Heavy alcohol consumption is a major problem in New Zealand, as an estimated two people die due to alcohol related causes per day and a policy requiring the increase of the price of alcohol is currently debated (Wannan, 2014). Flying (commercial aviation) should be familiar as it is the most frequently used mode of travelling to and from the New Zealand. All data was collected before the disappearance of Malaysian Airlines flight MH370 on the $8^{\text {th }}$ of March 2014, thus the event should not have affected the ratings for the 'flying (commercial aviation)' item. Nuclear power is arguably the hazard that participants may be most removed from, because New Zealand has no nuclear power plants. Yet the hazard was chosen because it showed the lowest results for risk tolerance in Slovic's studies and it is also important to the New Zealand Government's nuclear free policy. One key aim was to include earthquakes, which as natural disasters, were not included 
in Slovic's studies. The inclusion of earthquakes allowed for identifying how they score on the different risk characteristics compared to the other hazards.

The second aim was to replicate Slovic's (1985) factor analysis and to test whether the same factor structure would emerge. The six hazards were deliberately framed as risks, not the outcomes of risks, whereas in the initial studies the distinction between risks and outcomes was not made (personal communication with Paul Slovic, 2013). In order to have a consistent wording across all hazards, the hazards were described as the risk rather than the potential outcome in the present study.

The third aim was to test if any of the risk characteristics predict risk tolerance. The total of 12 risk items were made up of nine variables from Slovic (1985) and three additional variables. Slovic's items consisted of: Voluntariness of the risk, immediacy of effects, knowledge about the risk, knowledge about the risk, control over the risk, newness, catastrophic potential, dread and severity of the consequences.

The three additional variables were: Number of people exposed to the risk, amount of harm and frequency. The number of people exposed to the risk was added because Slovic (1987) suggested that this variable represented a third factor in some studies. The variables about estimated harm and frequency were added because research has shown that the distinction between high frequency-low impact events and low frequency-high impact events affects risk perception and preparation (McClure, Sibley, \& Rose, 2013). For example it is common that people lock their car to protect themselves from car theft (high frequency - low impact event), while the same people may not prepare for an earthquake even though it has a much higher impact, but occurs less frequently (Botzen et al., 2012). The frequency variable was of interest because 
many public risk communications focus on frequencies, especially in regard to low frequency events like earthquakes (McClure et al.,2013).

Three items assessed risk tolerance in terms of judgments about whether there should be stronger legislation to mitigate harm from the hazard, whether the local or national government should allocate more funds towards the mitigation of this hazard and how much people would be willing to pay in form of taxes to mitigate the risk.

In sum, this study replicates in part Slovic's (1985) psychometric risk characteristics study, assesses whether psychometric properties of hazards predict how risk tolerant people are of the different hazards and examines how major earthquakes score on the risk characteristics dimension. 


\section{Method}

\section{Participants}

The 139 participants were members of the Wellington public who voluntarily participated by coming to a stand that was prepared at the Wellington Harbourside Market. A poster explained that they could participate in this study and would receive a chocolate bar for filling in the surveys.

\section{Design}

Participants were presented with a questionnaire, which asked them to rate hazards on 15 different risk characteristics items. Because filling in six questionnaires for all six hazards would have been too time consuming, each participant completed ratings for three hazards only. The order of the hazards was randomised by filing the surveys in a random order before handing them to the participants. Slovic (1985) collected the data in the following way: "Insofar as Study 2 sought to examine three times as many hazards and twice as many risk characteristics as Study 1, no participant completed the entire task. Instead, two groups (42 individuals in one and 45 in the second) shared the assignment of judging the perceived risk and the need for risk adjustment. Each group judged a different set of 45 hazards."(Slovic, 1985). Rather than each participant responding to the same three hazards, the current study randomized the order of all hazards so that hazard judgments were not influenced by judging the same three hazards. For example if nuclear power and strong earthquakes were always judged one after the other it could be that the presence of one hazard has an effect of how the other is judged.

\section{Materials}


The survey consisted of six versions of a single page that contained all questions for one hazard. Each sheet had the instruction "On the 15 scales below, please rate the following hazard" followed by one of the six hazards. Each instruction and hazard was followed by all 15 questions.

The original article by Slovic et al. (1985) presented the results as a mixture of hazard risks and hazard outcomes, such as commercial aviation as well as plane crashes. After contacting the author and receiving further material from him (Slovic, 1999), it was decided to frame the label of the hazard as the activity, event or hazard itself not as the potential outcome of the risk. Thus in items where Slovic et al. described the hazard in terms of consequences (e.g., 'smoking related diseases') the item read 'smoking'. Thus people were asked to focus on the hazard itself not on the negative outcomes that may result from the hazard.

The six hazards were: Living in an area prone to strong earthquakes, smoking, heavy alcohol consumption, flying (commercial aviation), driving motor vehicles and nuclear power. In all questions, the activities, events, or technologies were called hazards rather than risks because people tend to think only of probabilities when they see the word risk (Slovic, 1999).

Nine of the 15 items were adapted versions of the risk characteristics reported by Slovic et al. (1987). Three further items were added to those reported by Slovic to create a total of 12 risk characteristics. These three were as follows: One item asked about the number of people exposed, because Slovic suggested that it represented another factor on some studies (1987). One item asking about the frequency of occurrence of each hazard and one item about the amount of harm were added because in relation to earthquakes, the research indicates that the distinction between low- and high- 
frequency and low- and high impact events is important for understanding how people perceive risk (McClure et al., 2013). Finally, a further three items representing risk tolerance were added.

Some of the items taken from Slovic's (1985) study were adapted in phrasing to achieve consistency over the meaning of the questions (see Appendix A for the full questionnaire). For example, the original first item read: "If you are exposed to the risk of each event, activity or technology, to what extent can you, by personal skill or diligence, avoid death?". Because all other items were phrased in the third person plural, this item was changed to: "To what extent can people, by personal action or diligence, avoid or control harm from this hazard?". The second item originally read: "Is this a risk that people have learned to live with and can think about reasonably calmly, or is it one that people have great dread for - on the level of a gut reaction?" and the anchor points were labelled "common" and "dread". Because the item talks about calmness rather than commonness, the anchor points were changed to "calm" and "dread".

The item "Is this a risk that kills people one at a time (chronic risk) or a risk that kills large numbers of people at once (catastrophic risk)?" was changed to " Does this hazard kill people one at a time or many people at once" in order to make the item easier to understand and less wordy. The ends of the scale were labelled "One at a time" and "Many people at once" instead of "Chronic" and "Catastrophic". The item: "When the risk from the activity is realized in the form of a mishap or illness, how likely is it that the consequence will be fatal?" was changed to "How likely is it that the consequences of this hazard will be fatal?" for the same reasons. The items: "Are these risks new, novel ones or old, familiar ones?" and "To what extent is the risk of death immediate or is death likely to occur at some later time?" were replaced with: "Is this 
hazard new and novel or old and familiar?" and "Are deaths from this hazard likely to be immediate or occur at some later time?".

To encourage participants to think about the particular hazard, the two items about knowledge about the risk were changed from "To what extent are the risks known precisely by the persons who are exposed to those risks?" and "To what extent are the risks known to science?" to "To what extent are the risks of this hazard known by the persons who are exposed to the hazard?" and "To what extent are the risks of this hazard known to science?". Finally, the question about voluntariness was adapted from "Do people get into these risky situations voluntarily? If for a single item some of the risks are voluntarily undertaken and some are not, mark an appropriate spot towards the center of the scale." to "Do people experience this hazard voluntarily?" in order to reflect that hazards like smoking or flying are experiences people can opt to have. Responses were on a 7-point Likert scale with anchor points 1 (voluntary) to 7 (involuntary).

Risk tolerance was measured in two ways: desire for stronger regulation and Willingness to Pay (WTP). The first item asked if people would like to see stronger legislation in order to mitigate harm from the relevant hazard. A desire for stronger legislation indicates low risk tolerance. However, risk tolerance is also defined as willingness to pay, thus there were two items assessing willingness to pay (WTP). The first asked if people thought the government should allocate more money towards the mitigation of the hazard and the second asked if people were willing to pay more in form of taxes or rates to reduce the hazard. These two items about WTP were used because people can agree with the government allocating more funds towards risk mitigation, but not be willing to pay more in form of taxes. The willingness to 
personally pay more is also a strong indicator for lower risk tolerance (Botzen et al., 2012). (See Appendix A for full questionnaire)

\section{Procedure}

Participants were approached and asked if they would like to participate in a short survey and receive a chocolate bar in return. Participation was voluntary. On completion, participants who were interested were given a debrief sheet which explained the survey once it was completed. 


\section{Results}

\section{Risk Characteristics for the different Hazards}

Table 1 displays the means for each of the six hazards on the 12 risk characteristics and the three risk tolerance variables. Following is a summary of some of the highest rating hazards. Heavy alcohol consumption had the highest mean on the 'Controllable' measure and nuclear power the lowest, closely followed by strong earthquakes. Nuclear Power had the highest rating on 'dread', 'kills many', 'amount of harm' and 'certain to be fatal'. Strong earthquakes had the highest rating on the 'many people exposed', 'involuntariness', 'unknown to those exposed' and 'unknown to science'.

In terms of the risk tolerance measures, nuclear power had the highest ratings for 'stronger legislation' followed by heavy alcohol consumption. People rated strong earthquakes and heavy alcohol consumption highest on 'more Government funds'. Strong earthquakes also had the highest mean for 'more tax' followed by nuclear power. On the three risk tolerance measures, people were most in favour of strengthening legislation and least willing to pay additional tax. 
Table 1

Means for 6 Hazards on all Characteristics

Earth
quakes Smoking Alcohol Flying $\quad$ Driving $\quad \begin{gathered}\text { Nuclear } \\ \text { Power }\end{gathered} \begin{gathered}\text { Overall } \\ \text { Mean }\end{gathered}$

\begin{tabular}{llllllll}
\hline Characteristic & & & & & & & \\
\hline Controllable & 3.50 & 5.86 & 5.99 & 4.47 & 5.28 & 3.45 & 4.76 \\
Dread & 4.67 & 3.34 & 3.12 & 4.11 & 3.15 & 4.87 & 3.88 \\
Kills Many & 6.03 & 3.12 & 2.94 & 6.00 & 3.96 & 6.23 & 4.71 \\
Certain to be fatal & 4.03 & 4.95 & 4.12 & 4.49 & 3.67 & 5.34 & 4.43 \\
Amount of Harm & 5.51 & 5.48 & 5.21 & 4.69 & 4.80 & 6.01 & 5.28 \\
Unknown (exposed) & 4.18 & 2.82 & 3.15 & 3.25 & 3.26 & 4.13 & 3.46 \\
Unknown (science) & 3.40 & 2.45 & 2.54 & 2.64 & 2.75 & 2.63 & 2.74 \\
Old & 6.10 & 6.15 & 6.27 & 5.06 & 5.54 & 4.68 & 5.63 \\
Delayed Death & 2.87 & 6.37 & 5.04 & 2.15 & 3.44 & 4.54 & 4.07 \\
Many Exposed & 6.15 & 5.43 & 5.44 & 4.88 & 5.42 & 5.59 & 5.49 \\
Frequency & 3.27 & 5.65 & 5.87 & 2.27 & 5.16 & 3.13 & 4.22 \\
Involuntariness & 6.30 & 2.69 & 2.50 & 3.96 & 4.06 & 6.00 & 4.25 \\
\hline Risk Tolerance & & & & & & & \\
\hline Stronger legislation & 4.61 & 5.19 & 5.34 & 4.15 & 4.93 & 5.68 & 4.98 \\
More Govt. funds & 5.09 & 4.65 & 5.09 & 3.75 & 4.93 & 4.70 & 4.70 \\
More taxes & 4.24 & 3.43 & 3.99 & 2.97 & 3.93 & 4.14 & 3.78 \\
\hline
\end{tabular}

$N=139$ as each participant rated half of the hazards. Each mean is based on half of the sample size (69-70).

Table 1. Means of all hazards on all risk characteristics.

\section{Factor analyses}

Factor analysis is a technique used to reduce responses in a data set to common underlying dimensions (Field, 2009). Exploratory factor analysis on the current study's data was used to identify if responses given in each hazard condition could be reduced to several underlying dimensions (factors). Confirmatory factor analysis aims to test if a data set fits the same factor model of another data set, and was used to test if the current data fits Slovic's 2-factor model. 
Testing Slovic's 2-Factor Model. Nine of the 12 risk characteristics scales were taken from Slovic's 1987 study in which a two factor solution emerged. The factors found in that study were identified as "Dread "and "Unknown Risk". Exploratory factor analysis using SPSS and confirmatory factor analysis using AMOS was undertaken on these nine scales to test whether the same two factor solution would be found with the current data.

Slovic's two factor solution showed that "severity of consequences" (certain to be fatal), "dread", "catastrophic potential" and "uncontrollability" grouped together to form the "Dread" factor. The second factor in their study, "Unknown Risk", was made up of "unknown to those exposed", "unknown to science", "newness", "delay of effects", "involuntariness" and "uncontrollability". The same variables making up the factors in Slovic's study were used in the following confirmatory factor analysis to test whether the data in the current study supports this model. A principal components (exploratory) factor analysis using Varimax rotation suggested a two factor solution in which some of the measures clustered together in a similar way to that found in Slovic (1987).

Confirmatory Factor Analysis (CFA) was then performed in AMOS to test the data against Slovic's (1987) two factor model. A CFA shows a good fit with the data when the Goodness of Fit Index (GFI) is higher than .90 and ideally above .95. A GFI of 1.0 indicates a perfect fit. The Root Mean Square of Approximation (RMSEA) and Chi square/df measures are 'badness of fit measures'. The RMSEA value should be smaller than .10 and ideally smaller than .05 , because larger values indicate a worse fit. The rule of thumb for the Chi square/df measure suggests that a figure lower than 2 indicates a good fit. The confirmatory factor analysis rendered a GFI of .91, a RMSEA 
of .13 and a Chi square/df value of 7.40. Thus the current data do not fit Slovic's model well. Because "uncontrollable" loaded onto both factors in Slovic's results, the analysis was repeated with "uncontrollable" in the second factor (Unknown Risk). This analysis rendered a goodness of fit (GFI) value of .91, a RMSEA value of .12 and a Chi square/df value of 7.22, not significantly better than the alternative model.

Identifying a reliable factor structure with Slovic's 9 items. To test for a factor structure that better matches the data of the current study, the sample of 413 response sheets (each participant filled in three hazard response sheets) was randomly split into groups of 206 and 207 response sheets. A two-factor exploratory analysis using Slovic's nine items was undertaken with the group of 206 responses and the factor structure found was tested using CFA on the responses of the 207 group.

This solution differed somewhat from Slovic's model with "catastrophic potential” (.77), “involuntariness" (.77), “uncontrollability” (.68), “dread” (.42), "immediacy of effects" (-.52) and "severity of consequences" (.33) grouping together. "Unknown to science" (.84), "unknown to those exposed" (.82) and "newness" (.41) grouped together as a second factor. These two factors were termed "Severity" and "Unknown Risk". The first factor (Severity) explained $27.3 \%$ of the variance, while the second (Unknown Risk) explained $16.7 \%$ of the variance. Together they made up $44 \%$ of the variance.

To test the model, a confirmatory factor analysis with the other 207 subjects was performed. Here the GFI was .96, RMSEA was .07 and the Chi square/df was 1.75 . These results indicate that the current study's data are better represented by the Severity and Unknown Risk Factor than Slovic's Dread and Unknown Risk Factors. 
Testing all 12 risk variables. Analyses were undertaken using all 12 scales, to test the utility of "frequency of harm", "amount of harm" and "number of people exposed”. First, an exploratory factor analysis using Varimax rotation was undertaken on the responses of the group of 206 participants including all 12 variables, i.e., the nine variables in Slovic's studies plus the three added variables ("frequency", "amount of harm" and "number exposed"). Factor 1 loaded on "catastrophic potential" (.77), "rarity" (low frequency) (.68), "involuntariness" (.65), "uncontrollability" (.59), "immediacy of the effects" (.52), "dread" (.46), "unknown to the exposed" (.41) and "unknown to science" (.29). Factor 2 loaded on "amount of harm" (.78), "severe consequences" (.75), "number exposed" (.55) and "newness" (-.41). "Newness" also (.40) also loaded positively on factor 1, while "rarity" also loaded negatively on factor 2 $(-.30)$

In order to achieve a two factor solution with clear and unequivocal factor loadings, items which seemed to be unreliable or load onto both factors, were deleted one by one. Thus in the final solution, "newness", "unknown to science", "dread" and "unknown to the exposed" had been deleted. The factor structure derived from the Varimax rotation for this solution was as follows. Factor 1: "catastrophic" (.78), “involuntariness" (. 71), "rarity" (.70), "uncontrollable” (.65) and "immediacy of effects" (.61); Factor 2: "amount of harm" (.83), "severe consequences" (.80) and "number exposed" (.54). This factor solution was then used for a Confirmatory Factor Analysis using the second group of 207 participants. This analysis showed a GFI of .92, a RMSEA of .12 and a Chi square/df value of 3.9. Thus this factor solution did not perform significantly better than the two factor solution suggested by Slovic and tested above. 
An alternative Exploratory Factor Analysis was undertaken on the twelve variables to see if a three factor solution would better represent the data. The factor structure presented as follows. Factor 1: "catastrophic potential” (.77), "rarity" (low frequency) (.70), "involuntariness" (.68), "uncontrollability" (.66), "immediacy of the effects" (.56), "dread" (.36) and "newness" (.31). The second factor was made up of: "amount of harm" (.78), "severe consequences" (certain to be fatal) (.71), "number exposed" (.55), "newness" (-.41), "dread" (.26) and "rarity" (.31). The third factor loaded on: "unknown to science" (.87), "unknown to the exposed" (.85), "newness" (.27) and "dread" (.32). It is to be noted that "dread" and "newness" load to almost equal amounts onto all three factors.

Because both "newness" and "dread" appeared to load on all three factors, they were deleted and a cleaner factor structure emerged with "catastrophic potential" (.77), “involuntariness" (. 71), "rarity” (low frequency) (.70), "uncontrollable” (.65) and "immediacy of effects" (.60) clustering together as one factor. "Amount of harm" (.82), "severe consequences" (.81) and "number exposed" (.53) clustered together as a second factor. "Unknown to science" (.88) and "unknown to exposed" (.86) made up the third factor.

The three factors were termed "catastrophic", "harmful" and "unknown" and a confirmatory factor analysis using those factors was performed. This analysis rendered a GFI of .92, a RMSEA of .10 and a Chi square / df value of 2.83. The overall fit of this model to the data is therefore very similar, but perhaps slightly better, than that found for two factors using all variables.

Thus of all the models tested, the two factor solution that had the best fit for the data represented the two factors "Severity" and "Unknown Risk" which only included 
the nine variables measured by Slovic et al. The two factor model with the factors "Dread" and "Unknown Risk" suggested by Slovic did not fit the data of the current study as well as this "Severity" and "Unknown Risk" solution. A two factor solution using the "Dread" and "Unknown Risk" factors from Slovic for testing if the three additional variables fit with this model also did not render a better fit. In fact, none of the two or three factor solutions including all 12 risk variables proved to be a good fit in the relevant CFA. The three additional variables ("rarity", "amount of harm" and "number of people exposed") did not contribute positively to the model.

Testing Risk Characteristics and Risk Tolerance Variables. To provide a visual indication of the relationships between all variables, the sample was reverted to its full size of 413 subjects and a two-factor exploratory factor analysis including all risk variables (not only the nine in Slovic's studies) and the intervention (risk tolerance) measures was performed. As an aid to interpretation, "old", "controllable" and "delayed" were included, together with new variables obtained by reversing the scores ("newness", "uncontrollable" and "immediate"). Only one of each reversed variable was entered into the analysis. The variables that clustered together in the first factor were "uncontrollable" (.76), "catastrophic potential” (.69), "involuntariness" (.64), “immediacy of effects" (.60), "frequency" (-.60), "dread" (.47) and "unknown to exposed" (.38). A second factor was made up of "more Government funds" (.67), "amount of harm" (.64), "stronger legislation" (.63), "more taxes" (.54), "severe” (certain to be fatal) (.47), "number exposed" (.47) and "old" (.46). These two factors cumulatively made up $37 \%$ of the variance.

The two dimensional plot shows that the risk tolerance scales ("more Government funds", "stronger legislation" and "more taxes") cluster together with 
"amount of harm", "severe consequences", "number exposed" and "old". The other scales that cluster together are "involuntariness", "catastrophic potential", "dread", "uncontrollable", "unknown to exposed", "unknown to science" and "immediate effects". This suggests that people tend to have a lower risk tolerance and thus desire more interventions for hazards to which many people are exposed, are old hazards, are very harmful and kill many people.

Multidimensional Scaling Analysis. As a non-metric alternative to component analysis, multidimensional scaling analysis with all variables and all participants was used to show how the different characteristics and intervention variables cluster together. This analysis also suggests that certain characteristics, namely "severe" (certain to be fatal), "amount of harm", "number of people exposed" and "old", are associated with the intervention variables Stronger Legislation and Stronger Government Funds. These characteristics may thus be the ones that people perceive as worth spending time and money on mitigating. The two factor solution which included the nine scales taken from Slovic's studies had the best fit for these data.

Correlations between factor solutions and Risk Tolerance. Correlations were performed between the different factor solutions and measures of risk tolerance. The two factors in the best two factor model, severity and unknown risk, did not correlate significantly with the composite variable made up of the three risk tolerance measures $(r$ $=.03, n s$ for severity, $r=.01, n s$ for unknown risk). When treated individually, the two factors also did not correlate significantly with the three risk tolerance scales. However, in the three factor solution, the factor made up of harm, severe and exposure, correlated with the composite risk tolerance measure $(r=.23, p<.01)$. Furthermore, this factor 
correlated with all three risk tolerance measures: stronger legislation $(r=.27, p<.01)$, more Government funds $(r=.19, p<.01)$ and with more taxes $(r=.10, p<.05)$.

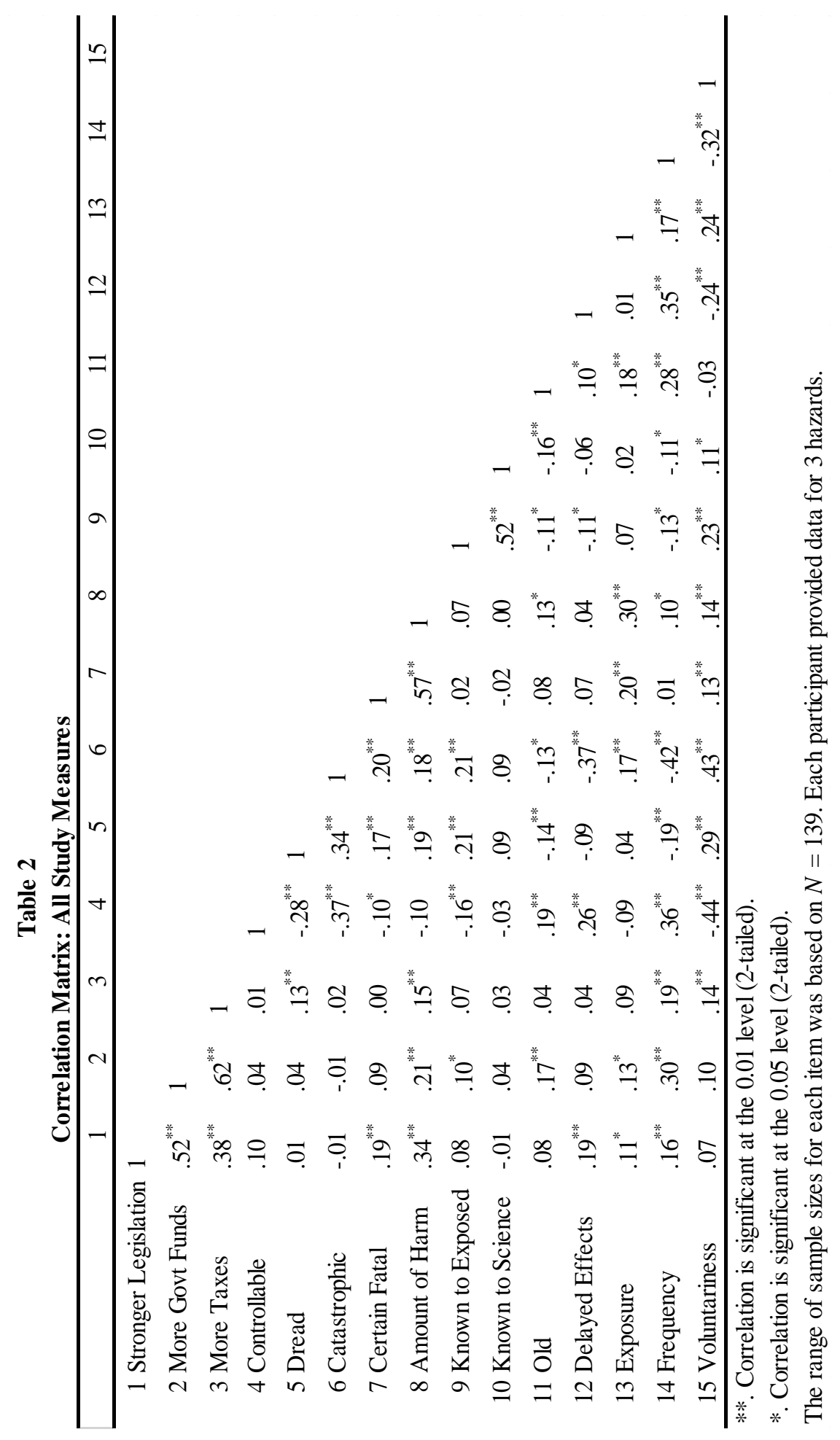

Table 2. Correlation matrix of all study measures. 


\section{Other Predictors of Risk Tolerance}

Correlations of all measures. Table 2 shows the correlations between all measures. Overall, stronger legislation had the highest mean rating $(M=4.98, S D=$ $1.51)$, followed by more government funds $(M=4.69, S D=1.53)$, and more taxes $(M=$ $3.78, S D=1.76$ ). Thus participants desired risk mitigation to take the form of increasing legislation rather than allocating more government funds or paying more tax. A repeated measures ANOVA showed that the risk tolerance ratings differed significantly, $F$ (2, 413) $=125.39, p<.001, \eta^{2}=.34$. Paired samples $t-$ tests showed that "stronger legislation" was rated higher than "more government funds", $t(412)=3.89, p<.001$, and than "more taxes", $t(412)=13.23, p<.001$, and "more government funds" was higher than "more taxes", $t(412)=12.75, p<.001$.

\section{Comparing different hazards on risk tolerance measures}

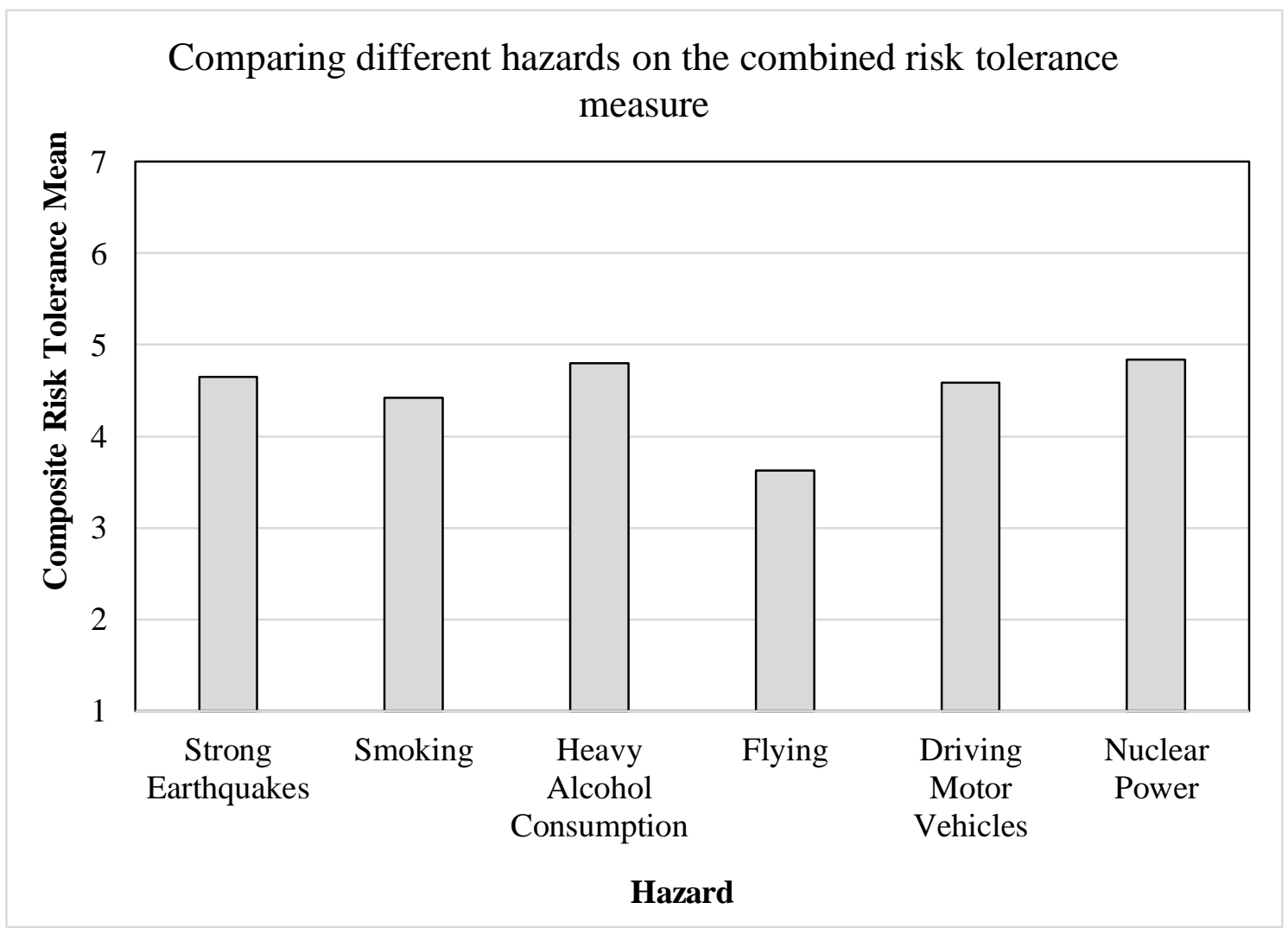


Figure 1. Means of the different hazards on the combined risk tolerance measure. A higher mean represents a lower risk tolerance.

Figure 1 displays the mean ratings (calculated as the mean of the three risk tolerance items combined) of the composite risk tolerance variable (combining legislation, more government funds, WTP tax) across all hazards. Nuclear Power $(M=$ $4.84, S D=1.28)$ had the highest rating, followed by heavy alcohol consumption $(M=$ 4.80, $S D=1.14)$, strong earthquakes $(M=4.65, S D=1.30)$, driving motor vehicles $(M$ $=4.59, S D=1.06)$, smoking $(M=4.42, S D=1.50)$ and flying $(M=3.63, S D=1.18)$. A one-way ANOVA comparing the six hazards on this variable showed that the different hazards differed significantly on these ratings, $F(5,412)=9.33, p<.01, \eta^{2}=.10$. Posthoc analyses using Tukey's HSD showed that 'flying' was rated significantly lower than all other hazards. These results show that participants had different levels of risk tolerance for the six hazards.

Figure 2 shows the mean ratings on each risk tolerance measure by hazard. A mixed-design (between subjects variable: hazard, within subjects variable: risk tolerance) ANOVA on the separate risk tolerance measures showed that there was a main effect for hazard, $F(5,407)=9.33, p<.001, \eta^{2}=.10$, and an interaction between hazard and risk tolerance measure, $F(5,407)=4.83, p<.001, \eta^{2}=.06$. The interaction shows that participants desire different levels of risk mitigation in the form of legislation, more government funds or paying more tax, depending on the hazard. For all hazards, except for strong earthquakes, ratings for stronger legislation were higher than increasing government funding. In contrast for earthquakes, paired samples $t-$ tests showed that more government funds was rated higher than stronger legislation $t$ $(67)=.30, p<.05$, and more taxes, $t(67)=4.67, p<.001$. 


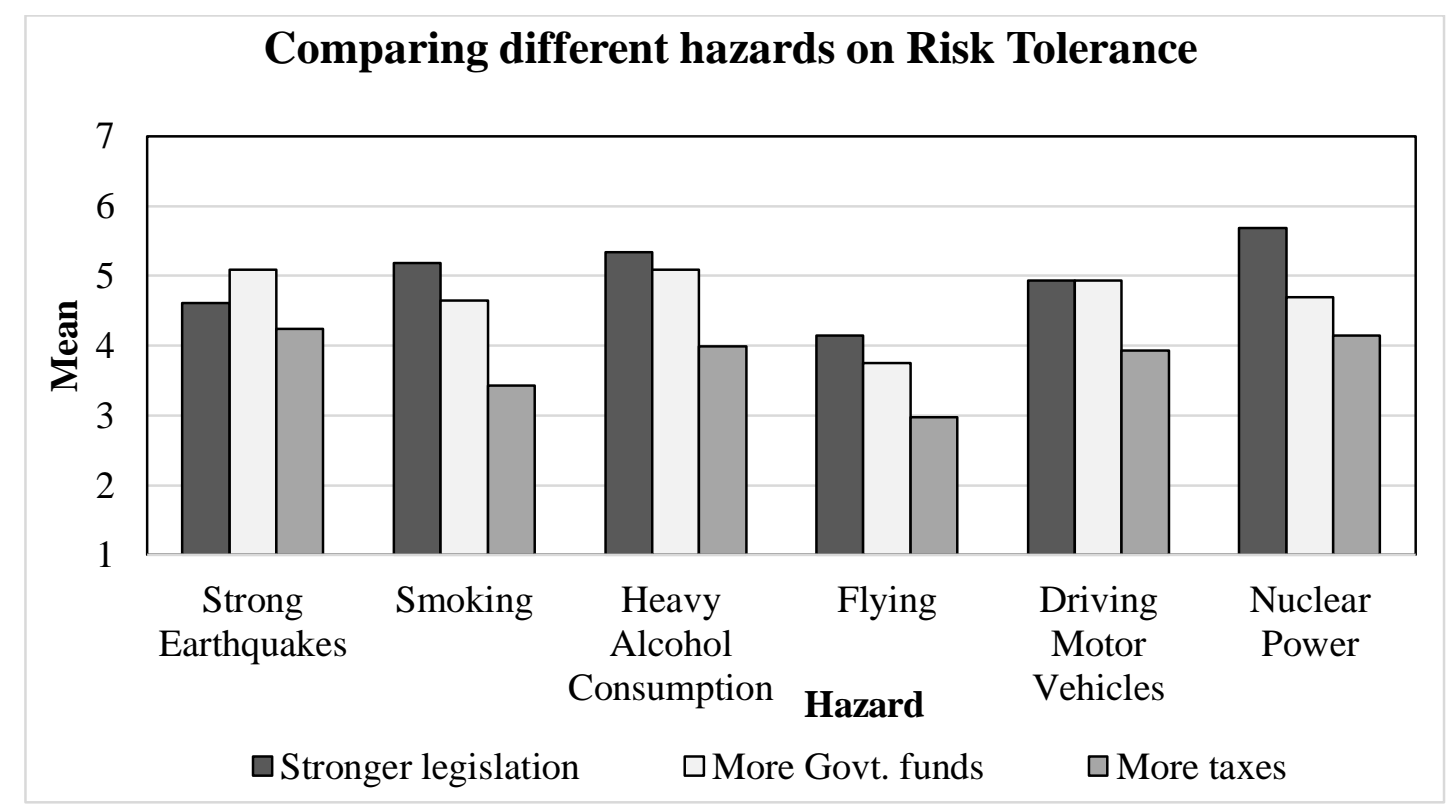

Figure 2. Comparing means of different hazards on each risk tolerance measure

\section{Predictors of Risk Tolerance}

All hazards. A simultaneous regression analysis was performed on predictors of the composite risk tolerance variable. This showed that the combined risk characteristics significantly predict the composite risk tolerance measure, $F(12,412)=7.60, p<.001$. The adjusted $\mathrm{R}$ square was $=.16$. All predictor variables are shown in Table 3. 'Amount of harm', 'frequency' and 'involuntariness' were significant predictors of the risk tolerance composite variable.

\begin{tabular}{|l|l|l|}
\hline Predictor & Beta & $\boldsymbol{p}$ \\
\hline Controllability & .07 & .20 \\
Dread & .04 & .40 \\
Kills Many & .04 & .52 \\
Certain to be fatal & -.08 & .15 \\
Amount of harm & .26 & $.00^{* *}$ \\
Unknown (exposed) & .08 & .13 \\
Unknown (science) & -.01 & .90 \\
Old & .02 & .73 \\
Delayed death & .08 & .11 \\
Many exposed & -.04 & .46 \\
Frequency & .28 & $.00^{* *}$ \\
Involuntariness & .20 & $.00^{* *}$ \\
\hline
\end{tabular}

Table 3. Predictors of risk tolerance. **. Significant to 0.01 level. 


\section{Earthquakes and Risk Characteristics}

Figure 3 displays the means for strong earthquakes across all 15 risk characteristics. It had high ratings on 'involuntariness', 'many people exposed', 'old', 'kills many' and 'amount of harm'. The lowest scores were observed on 'delayed death', 'high frequency' and 'unknown to science'.

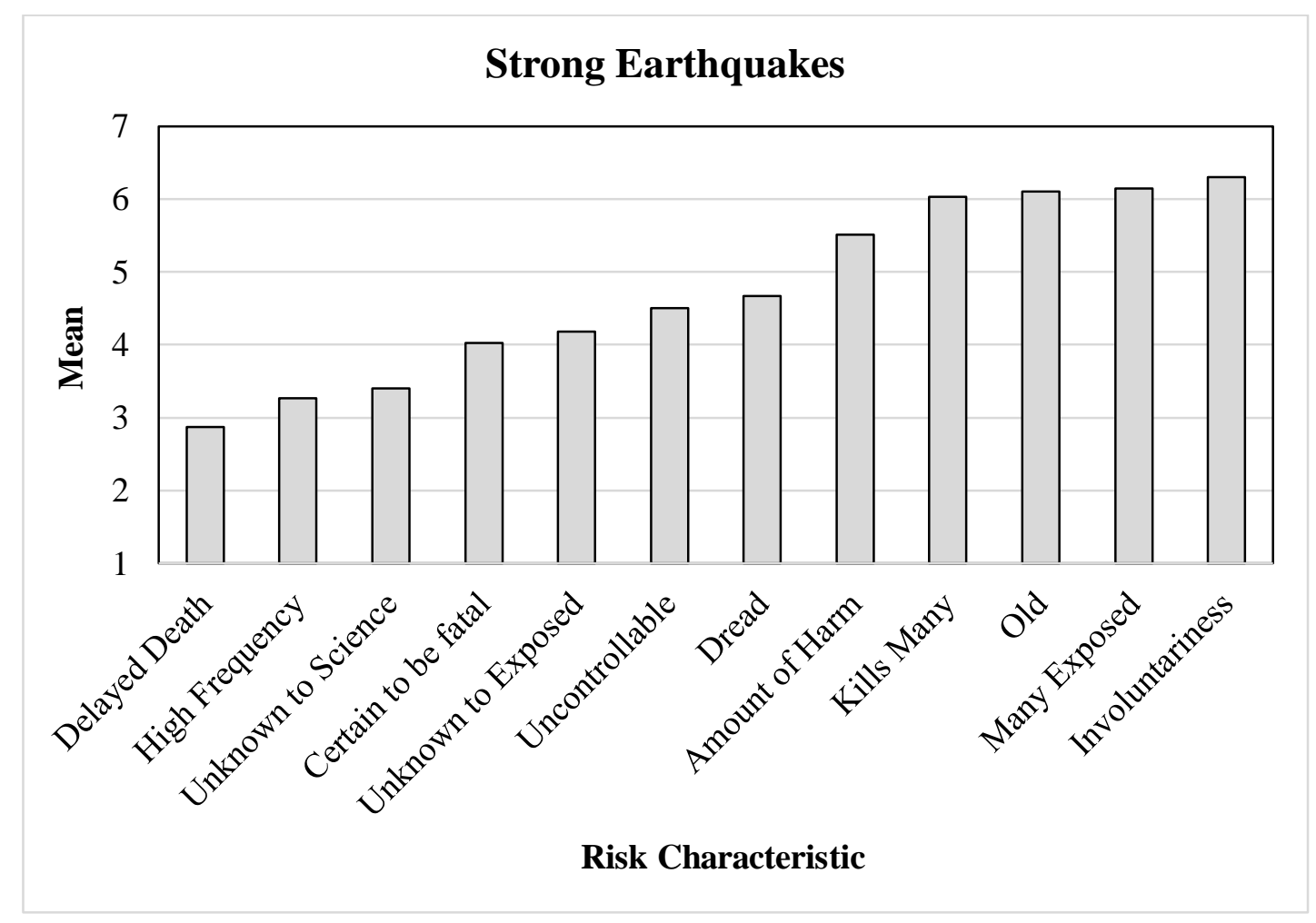

Figure 3. Risk Characteristics Ratings for Strong Earthquakes

Predictors of earthquake risk tolerance. Regression analyses was performed on earthquake risks.

Composite risk tolerance variable. A simultaneous regression analysis was performed on the earthquake hazard. Predictor variables were all 12 risk characteristics, and the dependent variable was the composite risk tolerance variable. The analysis was not significant, $F(12,66)=1.58, n s$. 
Stronger Legislation. A simultaneous regression analysis was performed on the legislation variable for earthquakes to test if any of the risk characteristics predict the desire for stronger legislation. The combined risk characteristics significantly predicted the stronger legislation measure, $F(12,66)=2.32, p<.05$. The adjusted $\mathrm{R}$ square value was $=.19$. The predictor variables are shown in Table 4. 'Controllability' und 'unknown to the exposed' were significant predictors.

\begin{tabular}{|l|l|l|}
\hline Predictor & Beta & $\boldsymbol{p}$ \\
\hline Controllability & .28 & $.02^{*}$ \\
Dread & .01 & .95 \\
Kills Many & -.11 & .37 \\
Certain to be fatal & .06 & .67 \\
Amount of harm & .03 & .82 \\
Unknown (exposed) & .44 & $.00^{* *}$ \\
Unknown (science) & -.28 & .05 \\
Old & .05 & .69 \\
Delayed death & .02 & .90 \\
Many exposed & .11 & .40 \\
Frequency & -.22 & .07 \\
Involuntariness & -.13 & .31 \\
\hline
\end{tabular}

Table 4. Strong Earthquakes - predictors of stronger legislation. **. Significant to 0.01 level.

More Government funds and WTP to pay more tax. The same analysis was performed for 'more government funds' and 'willingness to pay tax' but none of the analyses rendered any significant predictors. 


\section{Discussion}

Study 1 examined how people perceive six hazards in terms of risk characteristics and risk tolerance. It partly replicated Slovic et al.'s (1985) factor analytic study and assessed whether patterns of risk characteristics predict participants' risk tolerance of those hazards.

\section{Factor Analyses}

In order to show whether the same risk characteristics as in Slovic et al.'s (1985) study predict risk tolerance in this study, several factor analyses were performed on the risk characteristic items. Exploratory and confirmatory factor analysis showed that a two factor model which used the same two factors, Dread and Unknown Risk, as in Slovic's studies, did not fit the current data well. A better fit was achieved in a two factor model consisting of the two factors Unknown Risk and Severity. However, these two factors did not relate to any of the risk tolerance outcome measures.

Comparisons between the different factor models. Slovic's two factor model was made up of Unknown Risk and Dread. The Unknown Risk factor was made up of six variables (unknown to exposed, unknown to science, newness, immediate effects, involuntary and uncontrollable). The Dread factor was made up of "dread", "severe consequences" and "catastrophic potential". In the analysis on the current data using Slovic's nine variables, the two factor model which best fitted the data was made up of two factors: Unknown Risk and Severity. In the current data, the Unknown Risk factor 
was made up of only three of the variables of Slovic's Unknown Risk factor (unknown to science, unknown to exposed and newness). The remaining three variables from Slovic's Unknown Risk factor were included in the Severity factor (catastrophic potential, involuntariness, uncontrollable, dread, immediate effects, severe consequences).

When all 12 variables were included in the analysis, a two factor solution also fitted the data better than a three factor solution. The factors on the two factor solution were Catastrophic (catastrophic potential, involuntary, rare, uncontrollable and immediate) and Harmful (amount of harm, severe outcomes and number of people exposed). The three factor solution had the same two factors except that "unknown to science" and "unknown to exposed" made up the third factor (Unknown Risk). This three factor model, however, had a worse fit than the two factor solution.

When comparing the two factor model which did not include the three added variables with the two factor solution that did, some overlapping characteristics were found. "Catastrophic potential", "involuntariness" and "uncontrollable" were found in the Severe factor of the first model (Slovic's variables) and in the Catastrophic factor in the second model (all variables included). No other variables overlapped in the two models. Because the first model which included only the nine Slovic variables had the better fit, it was concluded that the three added variables (frequency, number of people exposed and amount of harm) did not contribute positively to the overall fit of the model. Thus the first two factor model (Severity and Unknown Risk), including only Slovic's original nine variables, best represented the current study's data and made up $44 \%$ of the variance. 
Multidimensional Scaling and best fit two factor solution. Multidimensional scaling analysis produces a visual representation of the characteristics that clustered together because of correlations. "Amount of harm”, "severe consequences”, "number exposed" clustered close to the risk tolerance measures (stronger legislation, more government funds and more taxes). Those three items also made up the Harmful factor in the two factor model that included all variables. Thus even though this two factor model had a worse fit than the model which only included Slovic's variables, it shows that these three items are related to one another. The multidimensional scaling analysis indicated that these items are related to risk tolerance measures. In sum, this combination of variables correlated with all of the risk tolerance measures.

The factor structure in Slovic et al.'s (1985) study may not have been replicated here for a number of reasons. The current study tested six hazards, including earthquakes, and compared their factor loadings on 12 risk characteristics. Slovic tested 30 hazards which were mainly activities and technologies and included no natural hazards such as earthquakes. In Slovic's studies, the hazards were described as both risks and outcomes of hazards, whereas the current study deliberately focused on risks not outcomes. It is possible that framing the hazards as outcomes, such as damage from earthquakes or nuclear power plant meltdown, might render different results (Slovic, 1999). Future research could clarify the effects of framing hazards as risks or outcomes.

Another factor is that this study framed the risk characteristics questions in general, impersonal terms as in Slovic (1985), e.g., "How likely is it that the consequences of this hazard will be fatal?". In contrast, the three items assessing risk tolerance are phrased in the first person, e.g., "Would you be willing to pay more in form of taxes or rates to reduce this hazard?". It is possible that participants thought 
about the average other or people in general for the risk characteristics and thought about their own personal circumstances for the risk tolerance measures.

In addition, in order to help people understand and answer the questions relating to the different risk characteristics, some of the original items from Slovic et al. (1985) were slightly changed in wording or shortened. It could be that shortening and simplifying the original items may have reduced the scale's reliability.

\section{Predictors of Risk Tolerance}

Slovic's (1985) research showed that hazards with high ratings on the Unknown factor and high levels of Dread predicted low risk tolerance and stronger desire for regulation. With the hazards tested in the current study, this particular structure of predictors could not be supported. The two factors that emerged in the current study were Severity and Unknown Risk, neither of which related to the risk tolerance measures. However, the results of the Multidimensional Scaling Analysis show that several individual characteristics of the six hazards, like the "amount of harm", "severity of the consequences" and "number of people exposed", were related to the risk tolerance measures. It is noteworthy that the "severe consequences" item also loaded highly on the Dread factor, which was the strongest factor predictor of risk tolerance in Slovic's (1985) study, so there is some consistency in the two sets of results.

A regression analysis found that across all hazards the "amount of harm", "high frequency" and "involuntariness" items predicted the composite of the three risk tolerance variables. "Amount of harm" and "frequency" were items that were added to the nine variables taken from Slovic's (1985) study, and show that the frequency with which hazardous events occur and the amount of harm they cause are important for understanding why people take preventative action, such as take out insurance, for some 
hazards and not others (Botzen et al., 2012). The "involuntariness" item was one of Slovic's original items and loaded consistently and highly on the Unknown Risk factor in Slovic's study. This finding further supports the claims in the first studies on the psychometric approach to risk tolerance, where voluntariness was presented as one of the most important determinants of risk tolerance (Slovic, 1987). A second regression performed solely on earthquake risk tolerance found that "controllability" and "unknown to the exposed" were significant predictors of the desire for stronger legislation for earthquakes.

The "controllability" item was another interesting variable which loaded highly on the factors found in both Slovic's results and the current data. In the two factor solution that best fitted the current study's data, "controllability" loaded onto the Severity factor. In Slovic's research, it was mainly the Dread factor that predicted desire for risk adjustment and "controllability" also loaded onto this factor. The controllability item in the current study predicted the desire for stronger earthquake legislation. These results suggest that the ability to control hazards is an important factor in predicting risk tolerance. In relation to this finding, McClure, Allen and Walkey (1999) found that people who had an internal locus of control, that is they believe that their own efforts or abilities have an impact on outcomes, were more likely to judge that damage from earthquakes and the causes of damage were preventable. The finding that controllability is an important factor for risk tolerance implies that people are likely to desire more regulation for hazards of which the outcomes are controllable.

\section{Risk Tolerance of the different hazards}

Differences across hazards. The ratings of all hazards on the different risk tolerance measures showed that people had different levels of risk tolerance for different 
hazards (Table 1). The lowest levels of risk tolerance were for nuclear power, followed by heavy alcohol consumption, strong earthquakes, driving motor vehicles, smoking and finally, flying. Participants also judged the three risk tolerance measures differently. Strengthening legislation was rated highest, followed by more Government funds and lastly, paying more tax. However, participants saw different risk tolerance measures as more appropriate for the different hazards. For earthquakes, they judged it more important to increase Government funds rather than requiring stronger legislation, whereas for the other hazards, they rated stronger legislation higher than increased Government funds and paying more tax. This suggests that in terms of mitigating risks from different hazards, a 'one size fits all' approach does not apply.

Participants had the lowest risk tolerance for nuclear power, strong earthquakes and heavy alcohol consumption. These three hazards will be discussed in more depth in the following section. Flying, Smoking and Driving had a higher risk tolerance and will be discussed in less detail.

Nuclear Power and Risk Tolerance. For nuclear power, participants rated it more important to have stricter regulation in the form of legislation, than for any other hazard. This result is consistent with research that suggests that catastrophic events such as the Chernobyl nuclear disaster in 1986 and recently the Fukushima Daiichi disaster in 2011, shape perceptions of risk for nuclear power technology (Slovic, 1987). Very few people die as a direct effect of these disasters, yet media coverage is extremely large. This pattern illustrates the availability heuristic, whereby risk perceptions and levels of tolerance are influenced by the media coverage of these events and the ease with which they are retrieved (Tversky \& Kahneman, 1973). 
In regards to the risk characteristics, nuclear power had high ratings on numerous risk characteristics. Nuclear power assumed a unique position in Slovic's research because it was the only hazard that scored high on both the Unknown Risk and the Dread factor. High ratings on the Dread factor especially predicted the desire for regulation in Slovic's (1985) study. In the current study, nuclear power also scored high on several items, i.e., on the "catastrophic potential", "severe consequences" (certain to be fatal), "amount of harm", "many exposed" and "involuntariness" items and had the highest rating on the composite risk tolerance measure (indicating a low level of risk tolerance). However, in this study, nuclear power was not the only hazard with high values for these characteristics. Strong earthquakes also scored high on several of these characteristics (amount of harm, catastrophic potential, many exposed and involuntariness). Therefore, the results of this study challenge the unique perception of nuclear power and show that strong earthquakes share some of the same (high) ratings.

Strong Earthquakes and Risk Tolerance. Strong earthquakes had high scores on "involuntary", “exposing many people", “old", "killing many people” and "amount of harm". They had low scores on "delayed death", "high frequency" and "unknown to science". Participants also rated earthquakes differently on the risk tolerance measures than the other hazards, in that they judged it more important to increase Government funds than to strengthen legislation, whereas for all other hazards the opposite pattern was found. This could be due to the current public debate in New Zealand about the proposed earthquake legislation and the intended standardisation of all building standards across all regions, regardless of their estimated earthquake propensity. The legislation is yet to be approved, but the debate is not only about whether the standardisation is a good idea, but also about who should pay for strengthening affected 
buildings (Hubbard, 2013). Participants may have been aware of the proposed legislation, but the issue of 'who should pay' has not yet been determined. The results suggest that citizens think that it should be the Government who should pay most of the cost for strengthening earthquake-prone buildings.

Heavy Alcohol Consumption and Risk Tolerance. In Slovic's (1985) study, alcoholic beverages scored low on both the Dread and the Unknown Risk Factor and participants did not desire more regulation. The current results are different to Slovic's results in that participants rated heavy alcohol consumption high not only on "controllable" and "newness", but also on "amount of harm", "many people exposed" and "high frequency". Heavy alcohol consumption had the second lowest risk tolerance. It also had the second highest rating for increasing legislation. This result may be due to the current media debate about the risks of high alcohol consumption in New Zealand (Wannan, 2014). Many New Zealanders are concerned with the issue and a proposed policy requiring a minimum price for alcohol was recently put on hold, despite the positive effects that similar policies have achieved in other countries (Wannan, 2014). National and international advertising campaigns particularly in relation to drink driving may also have contributed to this result.

Flying, Smoking and Driving and Risk Tolerance. In Slovic's (1985) study, smoking and motor vehicles were low to moderate on both the Dread factor and the Unknown factor. In the current study, participants rated smoking and driving high on the "controllable" and relatively low on the "involuntariness" scale. Participants also wanted moderately more legislation for the two hazards, yet less than for nuclear power, strong earthquakes and heavy alcohol consumption. 
In Slovic's (1985) study, commercial aviation was high on the Dread factor but low to moderate on the Unknown Factor. In the current study, flying had the highest risk tolerance, which suggests that participants may have perceived flying as a relatively safe hazard, which needs no further risk adjustment. The difference between perceptions and risk tolerance regarding flying between Slovic's 1985 study and the current study is likely to reflect that flying is safer than it was in 1985. The difference thus highlights the difficulty of comparing data collected almost 30 later and the change in perception may represent real changes in the status of the risk related to this hazard.

\section{Summary}

In summary, the factor analyses showed that a reliable factor solution was found, but it was slightly different from Slovic's (1985) factor structure. In addition, the risk characteristics factors in the best two factor model did not reliably predict risk tolerance for these six hazards. However, one factor (Harmful) from the three factor model, which included 12 variables and consisted of "amount of harm", "severe consequences" and "number exposed" did. Additionally, individual items that correlated with the composite risk tolerance variable for all hazards were "amount of harm", "number of people exposed" and "severe consequences". Participants perceived the six hazards differently in terms of risk tolerance and stronger legislation was rated highest and paying more tax lowest. However, they thought that different risk mitigation actions are appropriate for the different hazards. For earthquakes, participants judged it more important for the government to allocate more funds rather than making legislation stronger, whereas the result was reversed for the other hazards. For earthquakes, the characteristics "dread" and "unknown to the exposed" predicted the composite risk tolerance measure and 
"controllability" and "unknown to the exposed" predicted desire for stronger earthquake legislation.

\section{Study 2}

Whereas Study 1 examined the psychometric approach as a predictor of risk tolerance, Study 2 explored other factors that could influence risk tolerance for earthquakes. The psychometric approach does not include descriptions of the costs and benefits of mitigation actions or information on how people and experts talk about these issues in the public sphere. Thus Study 2 focused on other possible predictors of risk tolerance of major earthquakes. First, it assessed the effects of framing of cost-benefit messages on risk tolerance for earthquakes. Secondly, it tested whether concern or fatalism relate to risk tolerance. Thirdly, Study 2 aimed to clarify how people think the costs of mitigation actions should be divided between national government, local government and private owners. This was of interest because public discussions about the topic are based not only on the cost of strengthening buildings but also on the question of 'who should pay?' (Hubbard, 2013).

Framing has previously been shown to relate to differences in judgments about risk perception (Yagamishi, 1997; Keller et al., 2006) and Fatalism (McClure et al., 2001). There are different ways in which risk perceptions can be manipulated. Yamagishi (1997) described the same likelihood of being killed either as a percentage or as the actual number of people who die and found that the latter description affected risk perception. Keller et al. (2006) showed affect-laden images to participants and found that triggering an emotional response affected risk perception. McClure et al. 
(2001) found that messages describing indiscriminate damage from earthquakes affected attributions of damage which contribute to fatalistic thinking. Similarly, Botzen et al. (2012) framed flood risks in relation to other hazards using risk ladders and found that the risk communications affected measures of risk tolerance.

Study 2 tested if different framing messages taken from newspaper articles affect perceptions of earthquake risk, levels of fatalism and risk tolerance, and judgments about the proposed earthquake legislation. To examine the effects of framing of costbenefit messages on risk judgments, three groups of participants read different newspaper article excerpts about the costs and benefits of earthquake strengthening. The first expressed the view that the costs of strengthening outweigh the benefits. This message used a conservative measure of risk and described the earthquake risk as annual fatality rates. The second message provided the view that the benefits outweigh the costs and described the risk using a broader, more inclusive definition of risk and the third was a neutral message, which was the control. Thus the different framing messages use different definitions of risk and Study 2 aimed to test if these differences affect risk tolerance and other measures. Because there is a lot of debate about who should pay for strengthening earthquake prone buildings, the study also examined judgments about how much of the cost the New Zealand government, local Governments and private owners should carry.

Thus this second study aimed at testing several factors that contribute to risk tolerance and showing whether messages about the costs and benefits of earthquake strengthening, as presented in the media, affected risk perception, risk tolerance, and support of the proposed earthquake strengthening legislation. It further assessed participants' judgments about how the costs should be divided. 


\section{Method}

\section{Participants}

Individuals $(\mathrm{N}=173)$ from the Wellington general public filled in the questionnaire at the Wellington Harbourside Market. Participation was voluntary and each participant received a chocolate bar as a reward.

\section{Design}

Participants were assigned to one of three priming conditions. Each condition had a different priming message followed by questions about concern, risk perception, risk tolerance and fatalism.

\section{Materials}

The questionnaire began with instructions to read framing statements and answer the following questions. There were three different message frames. The first was termed the 'over-reaction message', which expressed the view that the costs of strengthening buildings outweigh the benefits. The second was called the 'underreaction' message and claimed that the benefits of strengthening outweigh the costs, while the third message was a control message. The over- and under-reaction messages differed in their use of statistical information on frequencies, likelihood of dying, definition of cost and comparisons to other risks.

Over-reaction messages. The first framing message was made up of two statements taken from New Zealand newspaper articles. The first statement was a quote 
from an interview with building design engineer Dr Peter Johnstone in 2001. He compared the likelihood of dying due to an earthquake and the likelihood of dying due to road accidents over a period of 80 years. In 2001 the annual road toll was approximately 500 people per year, which means that 40,000 people were killed over an 80-year time frame and a population of 4 million. This equated to a risk of 1/100 of being killed on the road. In 2001, fewer than 300 people had been killed over 80 years due to earthquakes (238 in the Napier earthquake in 1931). This statement thus uses statistical information about the annual likelihood of dying due to two different causes and compares them to each other. Furthermore, the message states that the risk of being killed on the road was one that people seem to accept, because there was no public debate about increasing funds into making roads better in New Zealand (Moran, 2001). This argument makes use of a number of factors. First, it compares the risk of dying due to an earthquake to a risk that kills many more people per year. Secondly, it uses the annual likelihood of being killed to define earthquake risk. Comparing this small likelihood to the financial cost of strengthening buildings therefore underpins the author's argument that the costs of strengthening all earthquake prone buildings heavily outweighs the benefits.

Because the article containing this excerpt was written in 2001 (i.e., before the 2010/2011 Christchurch earthquakes), the statistics were updated and recalculated. Thus the annual road toll today is closer to 400 and over the past 80 years 430 people have died in earthquakes (including 258 in Napier and 172 in Christchurch). With the numbers updated, over 80 years 32,000 people die on the road on average, which is slightly below a 1 in a 100 chance (.08) for a population of 4 million. The likelihood of 
being killed due to an earthquake was also recalculated and thus increased to 5.24 deaths per year, rendering a chance of dying of 1 in 10,000 over 80 years.

The second 'over-reaction' statement by Win Clark (2012), a Wellington based structural engineer, claimed the likelihood of being killed due to an earthquake as 1 in 1 million, considering historical factors (not only over the past 80 years). The argument compares this likelihood to the likelihood of being killed in a motorcycle accident $(1 \mathrm{in}$ $700)$ and that of being killed as a pedestrian or in a car (1 in 10,000) and equates the likelihood of being killed in an earthquake to that of being struck by lightning. This message also uses comparative risk to describe the risk of being killed due to an earthquake. It defines risk as the low likelihood of being killed, and the low frequency of earthquake occurrence. (See Appendix B for full messages)

Under-reaction messages. The second priming message was made up of two short statements also taken from newspaper articles which appeared in the Dominion Post (2013). The first statement describes the financial cost of strengthening all earthquake prone buildings across New Zealand ( $\$ 1.7$ billion) and compares it to its estimated benefits ( $\$ 37$ million). However, the statement then compares these costs to the costs of not preparing, including the loss in production and business opportunity. Finally, the statement compares the cost of rebuilding Christchurch ( $\$ 40$ billion) to the estimated $\$ 1.7$ billion cost of strengthening buildings across New Zealand.

This message defines cost differently to the two over-reaction messages. It focuses on the cost of not preparing and compares it to the events in Christchurch. Also, comparing the cost of rebuilding a city to the cost of strengthening buildings gradually, has the effect of making the cost appear comparatively small. This message does not 
include information about annual fatality rates, comparisons to other hazards or information about statistical frequencies of occurrence.

The second 'under-reaction' statement is from an article by Ann Brower (2013), a senior lecturer in public policy at Lincoln University. She was the only survivor on a bus that was crushed by unreinforced masonry during the Christchurch earthquake in February 2011. She argued that the Government's cost-benefit analyses only consider the financial cost of strengthening buildings which will be largely carried by the taxpayer. She argued that cost-benefit analyses need to consider the cost of not preparing. Her definition of cost also includes human pain and suffering, not just fatality rates. She compared not reinforcing the $8-13 \%$ of earthquake prone buildings to a situation where the same percentage of cars on the road had faulty brakes and accepting that they will fail at some unknown point in time.

Her argument claims that the number of people exposed to the risk is large (all of the public) and that the outcomes of earthquakes can be catastrophic. This message does not contain a statement about the low frequency of these events, but rather it states that everyone is at risk at all times because it is uncertain when a major earthquake could occur. (See Appendix B for full messages)

Control message. The third message was a control message. The statements were taken from an article which appeared on stuff.co.nz and describes the pros and cons of living in Christchurch after the earthquakes (Horan, 2014). The author points out that his favourite food places had gone, that he and his wife temporarily moved in with his parents in law and that his office was relocated to a garage for a while. This message was chosen as a control because it describes the pros and cons of living in 
Christchurch but it contains no judgments about the costs and benefits of strengthening buildings. (See Appendix B for full message)

All messages were equalized in terms of length so that each message was about 190 words long. The order of the two statements in each of the over and the underreaction message was randomised to counter order effects. To ensure that participants read the priming statements, a question asked participants to estimate how much the issues contained in the statements mattered to them (concern) and to write down any comments.

Frame messages were followed by eight questions. The first question on earthquake risk perception read: "How likely are you or your household to be affected by a major earthquake? Please give your rating on a scale from 1 to 7 , where $1=$ Extremely low probability and 7 = Extremely high probability.” This question was adapted from Botzen, van den Bergh and Aerts (2008). The original question was translated from Dutch and read "How high do you estimate the probability that your household will suffer financial damage on property due to the events mentioned below?" In order to simplify the question and relate it to earthquakes only, the question was reworded to the first version above.

The second question assessed participants' risk tolerance using the WTP paradigm, and read "How much would you be willing to pay in additional tax and/or rates per month, if any, for the purpose of strengthening earthquake prone public buildings?'. This was followed by a 10 - point scale which ranged from ' $\$ 0$ ' to over ‘ $\$ 100 ’$, with \$10 intervals. The question was based on a question about willingness to pay (WTP) for flood insurance in Botzen, van den Bergh and Aerts (2008), which asked "If you could get an insurance that completely covers flood damage on your house and 
home contents, would your household be willing to pay for it?". If participants answered 'yes' they were then asked "Can you indicate how much your household is willing to pay for this insurance per month?". Participants were presented with a table of amounts in Euro similar to the one in the current study, ranging from ' 0 ' to 'More than 120 Euro', from which participants could choose an amount.

Because in the Netherlands no all-encompassing flood insurance is available, Botzen et al. were interested in the WTP for insurance. In New Zealand, risk of damage from earthquakes is partially addressed by legislation on earthquake prone buildings, thus the question in the current study asks about WTP in form of tax or rates rather than insurance.

This question was followed by a short paragraph describing the new earthquake legislation, followed by two questions. The first question was "Do you think the proposed legislation is not firm enough, about right or too firm?" with a seven - point Likert scale ranging from 1 'Not firm enough' to 7 'Too firm'. A second question asked "Who do you think should pay for strengthening earthquake prone public and commercial buildings?" and gave three options (the New Zealand Government, Local Councils, Private Owners), each with a 7 - point Likert scale ranging from $1={ }^{\text {'None of }}$ the cost' to $7=$ 'All of the cost'.

The following questions related to fatalism adapted from McClure, Allen and Walkey (2001). A first question about controllability read "To what extent can people, by personal action, reduce harm from strong earthquakes?" with a 7 - point Likert scale ranging from 1 'Uncontrollable' to 7 = 'Controllable'. A question about preventability read "How likely is it that something can be done to prevent deaths from strong 
earthquakes?" with a 7 - point Likert scale ranging from $1=$ 'Highly Unlikely' to $7=$ 'Highly Likely'.

\section{Procedure}

Participants were approached at the Wellington Harbourside Market and asked if they would like to participate in a study about earthquake risk perception. If they agreed, they were handed one of the three framing versions of the survey and instructed to read the message on the front side of the page before answering any questions. Once they completed all questions, they received a chocolate bar of their choice as a reward for their participation. 


\section{Results}

Table 5 displays the Means and Standard Deviations for all dependent variables.

\begin{tabular}{|l|c|c|}
\hline \multicolumn{2}{|c|}{ Descriptive Statistics } \\
\hline & Mean & $\begin{array}{c}\text { Std. } \\
\text { Deviation }\end{array}$ \\
\hline Issue Matters (concern) & 5.04 & 1.42 \\
EQ Risk & 4.35 & 1.73 \\
WTP Tax & 2.74 & 2.50 \\
Legislation not firm & 4.51 & 1.21 \\
enough & 4.49 & 1.53 \\
Who Pay NZ Govt & 3.88 & 1.46 \\
Who Pay Council & 3.92 & 1.56 \\
Who Pay Private & 4.09 & 1.41 \\
Controllability & 4.52 & 1.50 \\
\hline
\end{tabular}

Table 5. Means and standard deviations of dependent variables.

Risk tolerance measures. The risk tolerance measures showed that people thought that the new legislation was close to 'about right' $(M=4.51, S D=1.21)$. The second measure, willingness to pay more in tax, had an overall low mean $(M=2.74, S D$ $=2.50$ ). As this rating was on a 10 - point Likert scale measuring monetary values, a mean of 2.74 represents a willingness to pay of $\$ 20-\$ 30$ more tax per month. 
Who should pay measures. The highest mean rating was for 'the government should pay more' $(M=4.49, S D=1.53)$, followed by Private $(M=3.92, S D=1.56)$ and Council $(M=3.88, S D=1.21)$. A repeated measures ANOVA showed that the means for the three 'who should pay' items differed significantly, $F(1,168)=10.26, p<.01, \eta^{2}$ $=.06$. Paired samples $t$-tests showed that 'NZ Government' was significantly higher than 'Council', $t(170)=5.28, p<.01$, and 'Private', $t(169)=3.20, p<.01$, whereas 'Council' and 'Private' did not differ significantly, $t(160)=0.27, n s$.

Fatalism measures. A repeated measures ANOVA showed that the mean ratings for preventability $(M=4.52, S D=1.50)$ were rated significantly higher than controllability $(M=4.09, S D=1.41), F(1,168)=10.10, p<.01, \eta^{2}=.06$.

\section{Effects of Priming}

There were no order effects for the different messages on any of the outcome variables. In order to test if the three priming messages had an effect on any of the dependent variables, several analyses of variance were conducted. The means and standard deviations for the 3 framing groups are shown in Table 6.

\begin{tabular}{|l|c|c|c|c|c|c|}
\hline \multirow{2}{*}{} & \multicolumn{2}{|c|}{ Over-reaction } & \multicolumn{2}{c|}{ Under-reaction } & \multicolumn{2}{c|}{ Control } \\
\cline { 2 - 7 } & Mean & Std. Dev & Mean & Std. Dev & Mean & Std. Dev \\
\hline Issue Matters (Concern) & 4.74 & 1.51 & 5.54 & 1.21 & 4.81 & 1.43 \\
Earthquake Risk & 3.89 & 1.67 & 4.18 & 1.93 & 4.64 & 1.73 \\
WTP Tax & 2.64 & 2.64 & 2.60 & 2.09 & 3.06 & 2.86 \\
Legislation not firm enough & 4.45 & 1.26 & 4.49 & .99 & 4.60 & 1.37 \\
Who Pay (NZ Govt.) & 4.48 & 1.66 & 4.58 & 1.40 & 4.44 & 1.48 \\
Who Pay (Council) & 3.84 & 1.53 & 3.95 & 1.45 & 3.93 & 1.34 \\
Who Pay (Private) & 4.09 & 1.68 & 3.65 & 1.53 & 3.82 & 1.52 \\
Controllability & 4.22 & 1.36 & 4.07 & 1.51 & 3.91 & 1.40 \\
Preventability & 4.30 & 1.58 & 4.57 & 1.50 & 4.65 & 1.47 \\
\hline
\end{tabular}

Table 6. Means and standard deviations for the framing groups. 
A one way between subjects ANOVA showed that the three priming messages had a significant effect on concern, $F(2,163)=5.58, p<.05, \eta^{2}=.06$. An independent samples $t$-test showed that the under-reaction message led to a higher rating on concern than the over-reaction message, $t(108)=-3.06, p<.05$, and the control, $t(108)$ $=2.87, p<.05$. There was no significant difference between the over-reaction message and the control, $t(108)=-.25, n s$.

A one-way between subjects ANOVA showed that the different frames had no significant effect on risk perception, $F(2,159)=.58, n s$, or legislation ratings, $F(2$, $162)=.04, n s$. A 3(Frame: Over-reaction, Under-reaction, Control) x 3(Who should pay: NZ Government, Local Councils, Private Owners) mixed design ANOVA was performed, where Frame was a between subjects variable and Who should pay was a within subjects variable. This showed that there was no main effect for the frame, but there was a main effect for the 'who should pay' variable, $F(2,169)=9.07, p<.01, \eta^{2}$ $=.05$. Participants rated the Government should pay more higher than the council $(M=$ 3.89, $S D=1.42), t(170)=5.28, p<.01$, and private owners $(M=3.84, S D=1.58), t$ $(169)=3.20, p<.01$. There was no interaction between frame and 'Who should pay', $F$ $(4,169)=.75, n s$.

A 3(Frame: Over-reaction, Under-reaction, control) x 2(Fatalism type: Preventability, Controllability) mixed design ANOVA was performed. The frame was a between subjects variable and the fatalism variable was within subjects. The results showed that there was a main effect for Fatalism type, $F(1,169)=10.18, p<.01, \eta^{2}=$ .06. Preventability was rated higher $(M=4.50, S D=1.52)$ than controllability $(M=$ 4.07, $S D=1.42)$. There was no interaction between frame and Fatalism, $F(2,169)=$ $1.97, n s$. In sum, the frames had an effect on concern but not on other variables. 


\section{Other Predictors of Risk Tolerance}

Correlations. Table 7 displays the correlation matrix for all variables.

Risk Tolerance. Willingness to pay in taxes was not related to any other items. The 'legislation not firm enough' item was positively related to the government should pay more' $(r=.17)$, thus people who thought that mitigation should be done through strengthening legislation thought the government should pay for it. Participants' concern ('issue matters') was related to 'legislation not firm enough' $(r=.26)$, showing that those participants who were concerned with the earthquake risk also thought that the legislation should be stronger.

Who should pay. 'The government should pay more' and 'local councils should pay more' are positively correlated $(r=.50)$, whereas 'the government should pay more' and 'willingness to privately pay more in taxes' were negatively related ( $r=-$ .49). This suggests that participants addressed the 'who should pay' question with a binary answer in that they thought it should either be the government (national or local) or private owners who pay.

Controllability correlated with preventability $(r=.34)$, 'the council should pay more' $(r=.22)$ as well as 'private owners should pay more' $(r=.22)$. Participants who believed that damage from major earthquakes is preventable indicated that private owners should pay more $(r=.31)$, whereas preventability was negatively related to wanting the New Zealand government to pay more for strengthening $(r=-.24)$. The risk perception measure did not relate to any of the other measures. 


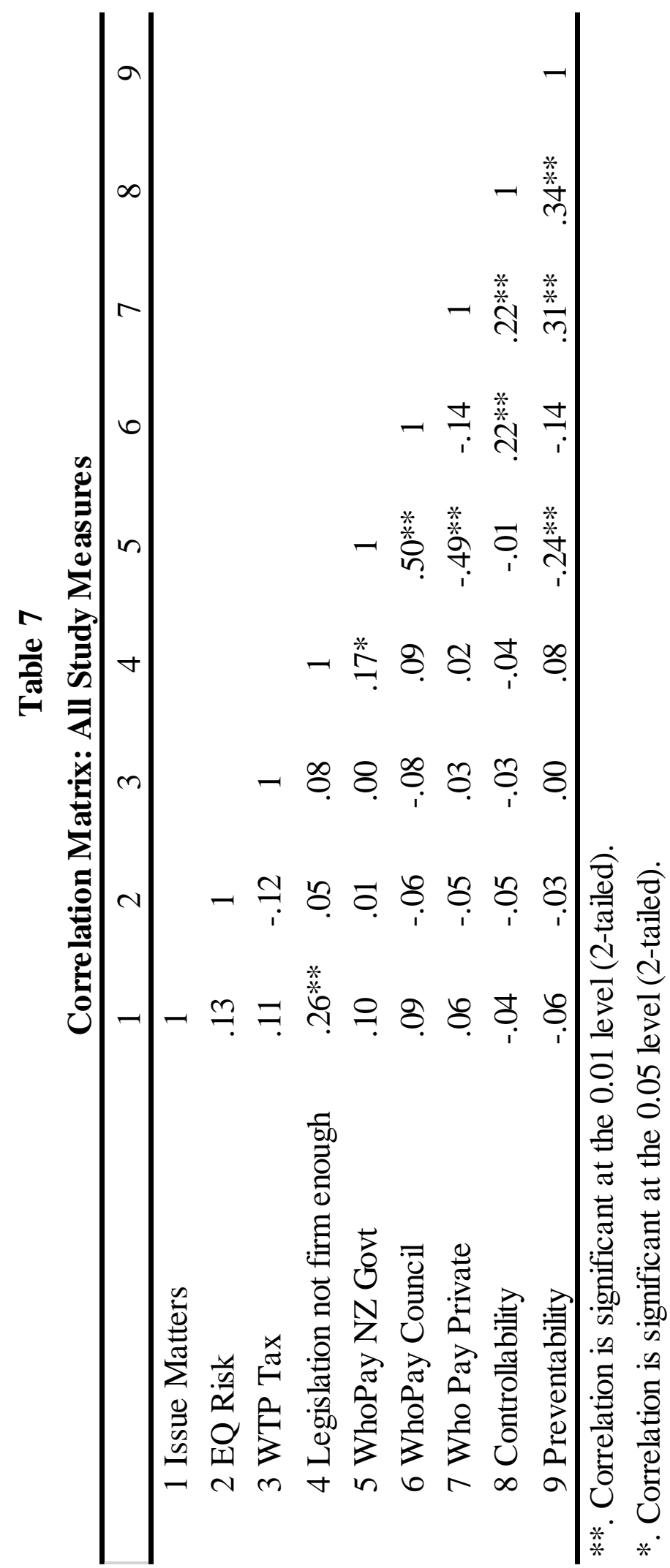

Table 7. Correlation matrix of all study measures. 


\section{Regression analysis}

A simultaneous regression analysis was performed to test if any of the tested variables predict the desire for stronger legislation. The result was significant, $F(7,163)$ $=3.23, p<.05$, adjusted $\mathrm{R}$ square $=.087$. The significant predictor variables were 'concern' and 'the government should pay more'. The results are shown in Table 8.

\begin{tabular}{|l|l|l|}
\hline Predictor & Beta & $\boldsymbol{p}$ \\
\hline Issue Matters (Concern) & -.25 & $.00^{* *}$ \\
Earthquake Risk & -.04 & .57 \\
Who Pay (NZ Govt.) & .21 & $.03^{*}$ \\
Who Pay (Council) & .04 & .64 \\
Who Pay (Private) & .10 & .27 \\
Controllability & .06 & .45 \\
Preventability & -.11 & .17 \\
\hline
\end{tabular}

Table 8. Results of regression on predictors of 'stronger earthquake legislation'.

Regression analysis on the second risk tolerance measure (WTP for tax) was not performed because none of the measures correlated with it. 


\section{Discussion}

Study 2 examined the relations of several variables to judgments of risk tolerance and who should pay. The framing variable presented arguments about costs and benefits of strengthening earthquake prone buildings across New Zealand. Other measures were concern, risk perception and fatalism.

Framing Effects. The framing messages had an effect on how concerned participants were about earthquakes. The under-reaction message produced a higher amount of concern than the over-reaction and the control message. However, the different frames had no significant effect on risk perception (measured as the likelihood of personally being affected by an earthquake), judgments about the firmness of the new proposed legislation and fatalism.

There are several possible reasons for the non-significant framing effects. First, Slovic et al. (1984) showed that pre-existing attitudes towards hazards and risk are hard to change. Since there is a lot of public discussion about the new legislation and its costs and benefits, participants were likely to have formed prior opinions on the topic. In contrast, when people lack prior knowledge about a hazard, they tend to base their risk judgments on the information presented to them (Slovic, 1984).

Second, the frames used in this study were messages that existed in the news media. In order to preserve the real world application of the study, the messages were not changed into highly experimentally controlled messages. Other studies in which tightly controlled framing messages were used found significant effects when manipulating specific parts of the framing messages (McClure, White \& Sibley, 2009).

A third point is that the frames expressed different levels of emotionality, but they did not use affect-laden imagery to trigger an emotional response. Previous 
research by Keller, Siegrist and Gutscher (2006) showed that evoking affect using images plays an important part in influencing risk perception. In their study, participants who looked at photographs of flood damage judged the likelihood of flooding as higher than participants who looked at neutral photographs. Thus affect-laden risk communication was able to increase risk perception. The current study did not find that the more affect-laden message (the under-reaction message) increased risk perception, although it did increase levels of concern significantly. Complementing the underreaction message with images of damage may have been more effective for influencing risk tolerance.

The priming messages in the current study presented risk as the annual fatality rate (over-reaction message) or the actual numbers of people killed, injured or traumatised in a recent earthquake (under-reaction message), but neither used a combination of the life-time timeframe and the relative fatality rate. Keller et al. (2006) found that when risk probabilities are presented in a time-frame which is within a lifetime (e.g. 50 years) people can relate to the probabilities more easily than when dealing with time-frames that extend a human life by far (e.g. 500 years). Yamagishi (1997) found that presenting participants with relative fatality rates, e.g. 1,268 out of 10,000, increased risk perception more than when using percentages, e.g. $24.14 \%$. Thus a lifetime timeframe and relative fatality rates, as seen in Crozier et al. (2006), may be an effective means of communicating risks for natural disasters. It is possible that such a combination would produce stronger effects on risk perception and tolerance.

Research on the effects of framing on fatalism showed that fatalistic beliefs are more difficult to change than attributions that lead to fatalistic thinking. McClure, Allen and Walkey (2001) found that showing participants messages about distinctive damage 
(as opposed to generalised damage) affected their judgments of preventability and increased attributions of damage to building design rather than the strength of the earthquake. The current study measured levels of fatalism by assessing judgments about controllability and preventability, yet it did not assess their attributions of damage, which are more sensitive to different messages. Research could examine whether the priming messages affect attributions.

Who should pay. There were significant differences in who participants thought should pay for strengthening public earthquake-prone buildings. Participants rated that the Government should pay the most, followed by private owners and the Council. The strong positive correlations between the 'Government should pay' and 'Councils should pay' and the negative correlations between those two items and 'Private owners should pay' indicate that participants thought it should either be a Government body (national or local) or private owners, more than both.

\section{Other Predictors of Risk Tolerance and Who Should Pay}

'The legislation is not firm enough' item was positively related to 'the Government should pay more'. This shows that participants who thought legislation should be used as a means for mitigating risk from earthquakes, were more likely to state that the Government should pay more. Historically, legislation has played a major role in reducing risk from earthquakes. Legislation in the form of building codes was introduced in New Zealand in 1935 following the Napier earthquake. A growing body of knowledge about seismicity and building material has led to many refinements over the years (Ministry of business, innovation and employment website, 2014). The current study's results suggest that increased legislation for minimising the risk of damage from earthquakes is in line with the trend in policy changes made in the past. 
Willingness to pay more in taxes was not related to any other item in this survey. Thus WTP was not affected by the frames and it also did not relate to other measures tested here. The same result was observed for risk perception. Framing messages did not affect risk perception and it was also did not relate to risk tolerance or other measures. This finding is not surprising as previous research shows that although risk perception can be influenced by framing, the effect did not extend to behavioural changes, for example, intending to prepare for an earthquake (Henrich, 2013).

However, concern related to measures of risk tolerance. Participants who were concerned with the issue were more likely to think that the legislation was not firm enough. This result suggests that risk communications which evoke concern relate to risk tolerance in that they may influence judgments about legislation. Concern is an affective response and therefore may be the most effective way of manipulating risk tolerance, as Keller et al. (2006) suggested.

Fatalism related to the question of who should pay in the following ways. Judgments of controllability and preventability were positively correlated, but they showed different relations to the 'who should pay' measures. Participants who thought that damage from earthquakes was controllable were also more likely to think that the Council or private owners should pay. In contrast, participants who thought that damage from earthquakes was preventable were more likely to say that private owners should pay. Thus the belief that damage is preventable may be a necessary basis for inferring that private owners carry some of the responsibility for paying for earthquake strengthening buildings. 


\section{Summary}

Frames expressing views on the costs and benefits of strengthening earthquake prone buildings affected concern but had no effect on measures of risk tolerance. Concern is important, because participants who were concerned were more likely to have lower risk tolerance and demand stronger legislation for dealing with earthquake prone buildings. In terms of fatalistic thinking, participants who thought that damage was preventable were more likely to state that private owners should pay for strengthening public buildings. Overall, participants thought that it was the Government's responsibility to pay for the strengthening of earthquake prone buildings - more so than the council, private owners or personally paying more in the form of taxes. 


\section{General Discussion}

This research firstly examined how participants perceive the risk of six hazards in terms of 12 risk characteristics and assessed how much risk mitigation in form of legislation, more Government funds or more taxes people desire for the different hazards (Study 1). Secondly, with regards to earthquake risk, Study 2 examined what relationships other factors, such as the framing of cost-benefit messages and fatalistic thinking, have to risk tolerance and judgments about who should pay for risk mitigation.

\section{Risk Perception and Risk Tolerance of different Hazards (Study 1)}

Study 1 examined whether a range of risk characteristics based on Slovic's (1985) findings predicted risk tolerance for six hazards. Slovic's model was not exactly replicated with the hazards studied here. The factor model that best represented Study 1's data was made up of the two factors Severe (catastrophic potential, uncontrollability, dread, delay of effects and severity of consequences) and Unknown Risk (unknown to science, unknown to the exposed and new). Three variables (Severe consequences, dread and catastrophic potential) in Slovic's strongest predicting factor (Dread) were the same as in the Severe factor found in this study. However, neither Slovic's factors (Dread and Unknown Risk) nor the current study’s best fit factors (Severity and Unknown Risk) and only the Harmful factor of the three factor solution predicted measures of risk tolerance in this study. This finding implied that the characteristics "severe consequences", "dread" and "catastrophic potential" tend to cluster together and are part of the same factor, but are not able to reliably predict risk tolerance.

Although the best factors in Study 1 did not predict risk tolerance, several individual risk characteristics did. A regression analysis showed that the risk characteristics items "involuntariness", "amount of harm" and "frequency" were all 
associated with the composite risk tolerance measure. However, reliable differences in risk tolerance based on psychometric factors as shown by Slovic et al. (1985) were not found in this study. In addition, with regard to earthquakes, the "controllability" and "unknown to the exposed" items predicted the legislation measure of risk tolerance. This implies that when participants perceive the risk of damage from earthquakes as controllable yet unknown, they are more likely to desire more regulation for earthquakes in the form of legislation.

\section{Other Potential Influences on Risk Tolerance (Study 2)}

Whereas Study 1 assessed risk characteristics as predictors of risk tolerance, Study 2 assessed whether other factors (framing, concern, risk perception and fatalism) related to risk tolerance and the question of 'who should pay?'. Counter to predictions, the framing messages had no effect on risk perception or measures of risk tolerance. Other studies have shown effects of framing on risk perception (McNeil et al., 1982; McClure et al., 2009; Botzen \& Van den Bergh, 2012). The non-significant effects in the current study suggest that many participants may have had strong pre-existing knowledge and strong attitudes towards the issue, which makes it more difficult for framing messages to change perceptions of the risk (Slovic, 1984). Yet there are ways of influencing risk tolerance. Botzen and Van den Bergh (2012), used risk ladders to communicate the increasing risk of flooding due to climate change. Keller et al. (2006) used imagery showing the effects of flooding. Both of these visual risk communications affected risk perception and risk tolerance. The frames in the current study may have been less effective in changing perceptions of risk and risk tolerance because they emphasised probabilities rather than visual representations or imagery. 
Although the framing messages about the costs and benefits of strengthening earthquake prone buildings did not affect risk tolerance, they did affect how concerned participants were about the issue. The 'under-reaction' framing message which had more emotional connotations had significantly higher ratings on concern than the 'overreaction' message. The 'under-reaction' message used actual numbers of people who died in the 2010/2011 Christchurch earthquakes, rather than the annual fatality rate presented in the over-reaction message. The use of fatalities relates to the "amount of harm" characteristic which, in Study 1, was a predictor of risk tolerance. Thus the way in which the amount of harm is presented may be important for levels of concern. Using frequencies rather than annual probability rates has been shown to provoke more affective responses which in turn increase levels of risk perception (Yamagishi, 1997; Keller et al., 2006; Botzen \& Van den Bergh, 2012). In the current study, concern was related to one of the key risk tolerance measures in that participants who were more concerned were more likely to judge that the proposed legislation is not firm enough. This finding implies that a description of risk which includes a broader criteria of risk as in the under-reaction message could affect risk tolerance through concern.

\section{Differences in Risk Tolerance and Who Should Pay}

In Study 1, participants perceived hazards differently in terms of risk tolerance and as requiring different risk mitigation strategies. This finding is in line with Slovic's (1985) research, which shows that participants desire different levels of risk reduction for different hazards. In Study 1, participants perceived strong earthquakes similarly to nuclear power in terms of risk characteristics and their risk tolerance was low for both of these hazards (high demand for risk mitigation). For all hazards except for earthquakes, strengthening legislation was the preferred risk mitigation action (over 
allocating more Government funds or paying more tax). However, the earthquakes hazard stood out on the risk tolerance measure, in being the only hazard for which participants thought it was more important to increase Government funds than to strengthen legislation. The results of Study 2, which focused solely on earthquakes, reinforce this finding in showing that participants thought that the Government should pay most of the costs for strengthening buildings. This implies that in regards to earthquakes, participants judged that it was the Government's responsibility not only to make legislation around earthquake prone buildings stricter, but also to pay for these changes.

\section{Fatalism and Perceived Control}

Previous research showed that fatalistic beliefs impact other related judgements about risk. Perceived control was shown to be an important factor by McClure et al. (1999), who found that people with an internal locus of control were more likely to attribute damage from earthquakes to building design rather than the force of the earthquake. In the current research, perceived control was an important item in both studies. In Study 1, the controllability item loaded on both Slovic's Dread factor and the current study's best fit model's Severity factor.

Study 2 found that judgments about the controllability and preventability of damage from earthquakes related to other measures, such as judgments about who should pay. Judgments about controllability were related to judgments about preventability as assessed in the fatalism measures. Yet, those judgments had different relationships with measures of who should pay. As discussed above, across all hazards, participants thought that it was the Government's responsibility to pay for risk mitigation. Judgments about preventability related to the 'who should pay' questions in 
that participants who rated damage as preventable were more likely to judge that private owners should pay more, as opposed to the Government paying more (which had the highest rating across the whole sample). This finding implies that risk communication messages which suggest that damage is preventable relate to participants' judgments about who should pay in that participants are more likely to state that private owners should pay. One way of increasing judgments about preventability is presenting distinctive damage that occurs due to questionable building design and avoiding reports about general, indiscriminate damage, as shown by McClure et al. (2001). Future research could test whether framing messages which manipulate perceptions of preventability affect judgments about private owners paying for strengthening and possibly extend to personal willingness to pay.

\section{Applications}

The results in Study 1 suggest that in order for policy makers to understand more about how people perceive different risks and how much regulation they desire, they need to consider several characteristics about the hazard. Specifically, in Study 1, the characteristics that related to different levels of risk tolerance were: how involuntary the hazard is, how severe the consequences are (how certain is it to be fatal) and also how large the amount of harm is.

Risk communications which describe risk in a way that people can easily relate to are useful for increasing risk perception and decreasing tolerance for a hazard (Botzen et al., 2012). Study 2 shows that concern was related to the belief that legislation on mitigating damage from earthquakes is not strong enough. The underreaction message, which used a more inclusive definition of costs and described risk as the actual number of people who are likely to die, led to higher levels of concern than 
the over-reaction message presenting annual fatality rates in comparison to other risks. Additionally, risk communication messages that suggest that damage is preventable and under personal control related to judgments about who should pay. Participants who perceived damage as preventable also tended to state that private owners are more responsible for paying for mitigation. This finding, applied to risk communications, should be used to encourage people to assume responsibility (and pay) for preventing damage from earthquakes.

\section{Limitations}

This research focused on six hazards, including earthquakes, in Study 1 and solely on the earthquake hazard in Study 2. In practical settings, when making decisions about funds for risk mitigation, policy makers need to consider other hazards than those that were chosen for Study 1. It could be beneficial to study more hazards, as Slovic (1985) did, or to use the same six hazards from Study 1 in a framing study in order to directly compare risk tolerance measures for all hazards across the two studies. A second point is that framing the hazards as risks (e.g. flying) may have different effects on measures of risk tolerance than describing the risk from hazards as outcomes (e.g. plane crash); however, the focus in this study was on the consistent description of hazards as risks not as outcomes. Future studies could determine if there is a stronger effect of describing hazards as outcomes on risk tolerance. In Study 1, one limitation is that the design of gathering responses for the different hazards necessitated treating the observations as independent in the factor analyses, when they were not. In future studies all participants should either rate all hazards or one participant should rate only one hazard. In Study 2, more controlled framing messages with more emotional tones and visual ways of describing risk might have produced stronger results. In terms of the 
amount that people indicated they are willing to pay, future studies should consider that this amount is also a function of their household and disposable income, not just their perception of risk tolerance. Thus adding a question asking about participants' income and what percentage of that they would be willing to contribute would be useful.

\section{Summary and Conclusions}

In summary, the best factor solutions derived from different risk characteristics did not predict risk tolerance for the six hazards in Study 1. However, some individual characteristics, such as "amount of harm", did predict the risk tolerance measures. In addition, for earthquakes, the amount of perceived controllability and how unknown the hazard is to those exposed predicted whether people thought relevant legislation should be strengthened. These results demonstrate that risk perception is complex and suggest that predicting risk tolerance using a limited number of risk characteristics is not straight forward. There are other factors, such as the effects that perceptual biases like the availability heuristic have on risk perceptions, which are not fully represented (and are hard to measure) in the psychometric paradigm. However, the results also suggest that different risk mitigation strategies should be employed for dealing with different hazards, as participants rated it more important to increase Government funds for mitigating risk from earthquakes, whereas they rated increasing legislation as more important for all other hazards.

The two studies showed that participants had a low risk tolerance for strong earthquakes and thought that Government should pay for risk mitigation. Messages about the costs and benefits of strengthening earthquake prone buildings may not directly affect risk tolerance, but they affected other judgments such as perceived controllability and concern which indirectly relate to judgments of risk tolerance and 
who should pay. Specifically, framing messages did not influence the measures of risk tolerance for earthquakes, but they did affect levels of concern, which in turn were related to the judgment that the legislation was not firm enough. Preventability was rated higher than controllability and may be an important factor for affecting judgments about who is responsible for paying for mitigation actions.

These findings clarify which factors do and do not relate to risk tolerance with hazards in general and earthquakes in particular. They thus inform strategies to lessen the devastating harm and loss that result from these events, in that they indicate which risk features public communications should focus on if they wish to influence tolerance for hazards. 


\section{References}

Baron, J.(2000). Thinking and Deciding $3^{\text {rd }}$ Edition. Cambridge: Cambridge University Press.

Botzen, W. J. W., De Boer, J., \& Terpstra, T. (2013). Framing of risk and preferences for annual and multi-year flood insurance. Journal of Economic Psychology, http://dx.doi.org/10.1016.j.joep.2013.05.007

Botzen, W. J. W.,\& Van den Bergh,J. C. J. M (2012). Monetary Valuation of Insurance againast Flood Risk Under Climate Change. International Economic Review, 53, $1005-1025$.

Botzen, W.J.W., van den Bergh, J. C. J. M., \& Aerts, J. C. J. H. (2008). Report on a Survey about Perceptions of Flood Risk, Willingness to Pay for Flood Insurance, and Willingness to Undertake Mitigation Measures: Explanation of the Survey Instrument.

Botzen, W. J. W., \& van den Bergh, J. C. J. M (2012). Risk attitudes to low-probability climate change risks: WTP for flood insurance. Journal of Economic Behavior and Organization, 82, $151-166$.

Brower, A. (2013, March 8). Time to put people before parapets. The Dominion Post, p. B1.

Bruine De Bruin, W. B., Fischhoff, B., Millstein, S. G., Halpern-Felsher, B. L. (2000). Verbal and numeral expressions of probability: "It's a fifty-fifty chance." Organizational Behavior and Human Decision Processes, 81, 115 - 131.

Clark, W. (2012). Perspective needed on quake risks. Dominion Post.

Cowan, J., McClure, J., \& Wilson, M. (2002). What a difference a year makes: how immediate and anniversary media reports influence judgements about earthquakes. Asian Journal of Social Psychology, 5, 169 - 185.

Crozier, M., McClure, J., Vercoe, J., \& Wilson, M. (2006). The effects of land zoning information on judgements about earthquake damage. Unpublished Manuscript.

Dominion Post (Anonymous author), Measuring the cost of time (2013, August 9). The Dominion Post, p. A12 or access at: http://www.stuff.co.nz/dominionpost/comment/editorials/9018996/Editorial-Measuring-the-cost-of-time

Fischhoff, B., Slovic, P., \& Lichtenstein, S. (1979) Weighting the Risks: Which Risks are Acceptable? In P. Slovic, The Perception of Risk London: Earthscan. 
Field, A. (2009). Exploratory Factor Analysis. Discovering Statistics Using SPSS $3^{\text {rd }}$ Edition (p. 628 -629). London: Sage.

Hammit, J. K., \& Graham, J. D. (1991). Willingness to Pay for Health Protection: Inadequate Sensitivity to Probabilities? Journal of Risk and Uncertainty, 88, 33 -62 .

Henrich, L. (2013). Effects of Framing on Earthquake Risk Perception and Judgements about Risk. Unpublished Honours Thesis, University of Wellington, New Zealand.

Horan, A. (2013). How has your life changed? Retrieved from http://www.stuff.co.nz/stuff-nation/assignments/chch-how-has-your-lifechanged/8469660/Chch-life-Resilience-and-buzz

Hubbard, A. (2013, July 27). Who Should Pay? The Dominion Post, p. C1.

Joslyn, S. L., Nadav-Greenberg, L., Taing, M. U., Nichols, R. M. (2009). The effects of wording on the understanding and use of uncertainty information in a threshold forecasting decision. Applied Cognitive Psychology, 23, 55 - 72.

Joslyn, S. L., Nichols, R. M. (2009). Probability of Frequency? Expressing forecast uncertainty in public weather forecasts. Meteorological Applications, 16, $309-$ 314.

Keller, C., Siegrist, M. \& Gutscher, H. (2006). The Role of Affect and Availability Heuristics in Risk Communication. Risk Analysis, 26, 631 - 121.

Klein, W. M. P. (2003). Self-prescriptive, perceived, and actual attention to comparative risk information. Psychology and Health, 18, 625 -643.

Kunreuther, H. (2006). Disaster Mitigation and Insurance: Learning from Katrina. Annals of the American Academy of Political and Social Sciences, 604, 208 227.

McClure, J., Allen, M. W., \& Walkey, F. (2001). Countering Fatalism: Causal Information in news Reports Affects Judgements About Earthquake Damage. Basic and Applied Psychology, 23, 109- 121.

McClure, J., Spittal, M. J., Fischer, R., \& Charleson, C. (2014). Clarifying why people take fewer damage mitigation actions than survival actions: How important is cost? Unpublished manuscript, Victoria University of Wellington.

McClure, J., Sibley, C., \& Rose, C. (2013). Failure to Prepare for infrequent hazards: Do people discount low frequency risks more if the damage cost is constant? Unpublished Manuscript, Victoria University of Wellington. 
McClure, J., Sutton, R. M., \& Sibley, C. (2007). Listening to reporters or Engineers? How instance-Based Messages About Building Design Affect Earthquake Fatalism. Journal of Applied Social Psychology, 37, 1956 - 1973.

McClure, J., Walkey, F., \& Allen, M. (1999). When Earthquake Damage is seen as Preventable: Attributions, Locus of Control and Attributions to Risk. Applied Psychology: An international Review, 48, 239 - 256.

McClure, J., White, J., \& Sibley, C. G. (2009). Framing Effects on Preparation Intentions: Distinguishing Actions and Outcomes. Disaster Prevention and Management, 18, $187-199$.

McNeil, B. J., Pauker,S. G., Sox, H. C., \& Tversky, A. (1982). On the Elicitation of Prferences for Alternative Therapies. The New England Journal of Medicine, $306,1259-1262$.

Ministry of Business, Innovation and Employment website (2014). Building and Housing Information, Earthquake prone buildings. Retrieved from: http://www.dbh.govt.nz/codewords-10-article-7

Moran, P. (2001, November 29). Big quake need not be a killer, says expert. Dominion Post Slovic, P., Fischhoff, B., \& Lichtenstein, S. (1985). Characterizing perceived risk. In R.W. Kates, C. Hohenemser, \& J.X. Kasperson (Eds.), Perilious progress: Managing the hazards of technology (pp. $91-125$ ). Boulder, CO: Westview.

New Zealand Police, Official fatality list, Retrieved from http://www.police.govt.nz/major-events/previous-major-events/christchurchearthquake/list-deceased.

Parliamentary Counsel Office, Building (Earthquake-prone Buildings) Amendment Bill, Retrieved from http://www.legislation.govt.nz/bill/government/2013/0182/latest/DLM5616102 .html.

Patt, A., Dessai, S. (2005). Communicating uncertainty: lessons learned and suggestions for climate change assessments. Comptes Rendus Geoscience, 337, 425 - 441.

Slovic, P. (1987). Perception of Risk. Science, 236, 280 - 285.

Slovic, P. (1999). Comment: Are trivial risks the greatest risks of all? Journal of Risk Research, 2, $281-288$.

Slovic, P. (2000).Informing and Educating the Public about Risk. In P. Slovic, The Perception of Risk (pp. 182-198). London: Earthscan.

Slovic, P. (07.11. 2013). Personal Communication. 
Slovic, P., Finucane, M., Peters, E., \& MacGregor, D. G. (2004). Risk as Analysis and Risk as Feeings: Some Thoughts about Affect, Reason, Risk, and Rationality. Risk Analysis, 24, $311-322$.

Slovic, P., Fischhoff, B., \& Lichtenstein, S. (1984). Behavioural Decision Theory Perspectives on Risk and Safety. Acta Psychologica, 56, 183 - 203

Slovic, P., Fischhoff, B., \& Lichtenstein, S. (1985). Characterizing perceived Risk. In R. W. Kates, C. Hohenmeister, \& J. X. Kasperson (Eds.), Perilious Progress: Managing the hazards of technology (pp. $91-125$ ), Boulder, CO: Westview.

Slovic, P., Kunreuther, H., \& White, G. F. (1974). Decision processes, rationality, and adjustment to natural hazards. In G.F. White (Ed.), Natural Hazards, Local, National and Global (pp. 187 - 205). New York: Oxford University Press.

Slovic, P., \& Weber. E. (2002). Perception of Risk posed by Extreme Events. Center for Decision Research (CDS) Working Paper.

Spielthenner, G. (2012). Risk-Benefit Analysis: From a Logical Point of View. Bioethical Inquiry, 9, $161-170$.

Spittal, M. J., McClure, J., \& Walkey, F. (2008). Predictors of Two Types of Earthquake Preparation. Survival Activities and Mitigation Activities. Environment and Behaviour, 40, $798-817$.

Stuff nation, Does New Zealand need an alcohol overhaul. Retrieved from http://www.stuff.co.nz/stuff-nation/assignments/8049725/Does-NZ-need-analcohol-overhaul

Tversky, A., \& Kahneman, D. (1973). Availability: A Heuristic for Judging Frequency and Probability. Cognitive Psychology, 5, $207-232$.

Tversky, A., \& Kahneman, D. (1974). Judgement under Uncertainty: Heuristics and Biases. Science, 185, $1124-1131$.

Van der Plight, J. (1996). Risk Perception and Self-Protective Behavior. European Psychologist, 1, $34-43$.

Wannan, O. (2014, April 26). Alcohol-pricing policy delay slammed. The Dominion Post, A1.

Wellington Airport Website (2014). Questions on extending the runway. Retrieved from: http://www.wellingtonairport.co.nz/about/questions-on-extending-therunway/. 
Wellington City Council, Earthquake-prone buildings. Refrieved from: http://wellington.govt.nz/services/rates-and-property/earthquake-pronebuildings/earthquake-prone-buildings.

Windschitl, P. D., \& Weber, E. U. (1999). The interpretation of "likely" depends on the context, but " $70 \%$ " is 70\% - right? The influence of associative processes on perceived certainty. Journal of Experimental Psychology, Learning, Memory and Cognition, 25, $1514-1533$.

Sabin, B. (2013). Calls for Wellington Airport to extend runway. Retrieved from: http://www.3news.co.nz/Calls-for-Wellington-Airport-to-extendrunway/tabid/421/articleID/281961/Default.aspx.

Yamagishi, K. (1997). When a $12.86 \%$ mortality is more dangerous than $24.14 \%$. Implications for risk communication. Applied Cognitive Psychology, 11, $495-$ 506. 


\section{Appendix A: Questionnaires Study 1}

\section{Hazard Questionnaire: Characteristics of Various Hazards}

Please rate the following hazard on the thirteen seven-point scales below.

(Each questionnaire had one of the following hazards printed up the top)

\section{Living in an area prone to Strong Earthquakes}

\section{Smoking}

Heavy Alcohol Consumption

Driving Motor Vehicles

Flying (Commercial Aviation)

\section{Nuclear Power}

(Each hazard was followed by these questions)

1. If people are exposed to this hazard to what extent can they, by personal action or diligence, avoid or control harm?
Uncontrollable
1
23

$\begin{array}{lll}4 & 5 & 6\end{array}$
7 Controllable

2. Is this a risk that people think about reasonably calmly, or is it one that people have great dread for - on the level of a gut reaction?
Calm
1
23
4
5
7 Dread

3. Does this hazard kill people one at a time or many people at once?
One at a time
1
2
4
567
Many people at once

4. How likely is it that the consequences of this hazard will be fatal?

$\begin{array}{llllllllll}\text { Certain not to be fatal } & 1 & 2 & 3 & 4 & 5 & 6 & 7 & \text { Certain to be fatal }\end{array}$

5. How large is the amount of harm that results from this hazard?
Little harm
12
3
4
56
7 Great harm

6. To what extent are the risks of this hazard known by the persons who are exposed to the hazard?

$\begin{array}{llllllllll}\text { Known precisely } & 1 & 2 & 3 & 4 & 5 & 6 & 7 & \text { Not known }\end{array}$

7. To what extent are the risks of this hazard known to science?
Known precisely
123
45
$\begin{array}{lll}6 & 7 & \text { Not known }\end{array}$

8. Is this hazard new and novel or old and familiar?
New
1
2
3
4
$\begin{array}{lll}5 & 6 & 7\end{array}$
Old 
9. To what extent is the probability of death from this hazard immediate or is death likely to occur at some later time?

$\begin{array}{llllllllll}\text { Immediate } & 1 & 2 & 3 & 4 & 5 & 6 & 7 & \text { Delayed }\end{array}$

10. How many people are likely to be exposed to this hazard?
Few people 1 3
4 56
$7 \quad$ Many people

11. How frequently do you think harm from this hazard occurs?

$\begin{array}{llllllllll}\text { Not frequently } & 1 & 2 & 3 & 4 & 5 & 6 & 7 & \text { Highly frequently }\end{array}$

12. Do people experience this hazard voluntarily?
Voluntary
$\begin{array}{lll}1 & 2 & 3\end{array}$
4
$\begin{array}{lll}5 & 6 & 7\end{array}$
Involuntary

13. Should there be strong legislation to mitigate harm from this hazard?
No
$\begin{array}{lll}1 & 2 & 3\end{array}$
45
$\begin{array}{lll}6 & 7 & \text { Yes }\end{array}$

14. Do you think local / national government should allocate more funds to reduce this hazard?

$\begin{array}{llllllllll}\text { Much less } & 1 & 2 & 3 & 4 & 5 & 6 & 7 & \text { Much more }\end{array}$

15. Would you be willing to pay more in form of taxes or rates to reduce this hazard?

$\begin{array}{llllllllll}\text { No more } & 1 & 2 & 3 & 4 & 5 & 6 & 7 & \text { Much more }\end{array}$




\section{Appendix B: Priming Messages and Questionnaires Study 2}

\section{Earthquakes Questionnaire}

The following statements are taken from actual newspaper articles following the Christchurch earthquakes. These statements may say exactly the same thing or slightly different things. Please read them carefully and then answer the questions on the next page.

\section{Statement 1:}

"So far, we have focussed on the cost of upgrading the buildings, which will be borne by owners, councils, and taxpayers. What about the cost of not fixing them, which will be borne by us? As we learned on February 22, 2011, the cost of not reinforcing is human pain.

... In delaying requiring reinforcements to dangerous buildings, estimated as 8 to $13 \%$ of New Zealand's buildings, the ministry is asking us to accept a known and preventable risk. It is like accepting that 8 to $13 \%$ of all cars on the roads have faulty brakes. We know they will fail, we just don't know when."

\section{Statement 2:}

"Yes, the financial benefit of bringing all buildings up to code might only be $\$ 37$ million and yes the cost of doing so might be $\$ 1.7$ billion. However, the price of not doing so can be far greater.

The cost of the Christchurch quakes must be measured not only in lost life and injury, but also in lost production and lost opportunity. At last count, the cost of rebuilding Christchurch had been put at $\$ 40$ billion. Beside that $\$ 1.7$ billion is a pittance."

Do the issues raised in these articles matter to you?

\begin{tabular}{|l|l|l|l|l|l|l|}
\hline $\begin{array}{l}\text { Not at all } \\
1\end{array}$ & 2 & 3 & 4 & 5 & 6 & 7 \\
\hline
\end{tabular}

Any comments 


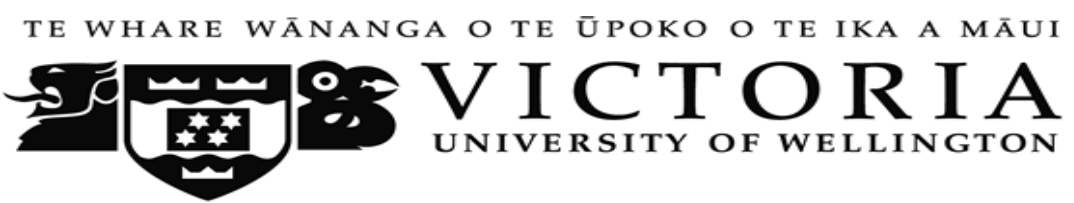

\section{Earthquakes Questionnaire}

The following statements are taken from actual newspaper articles following the Christchurch earthquakes. These statements may say exactly the same thing or slightly different things. Please read them carefully and then answer the questions on the next page.

\section{Statement 1}

"Taking into account historical factors, the risk of being killed by an earthquake in New Zealand is one in a million. That compares to the risk of one in 700 of being killed in a motorbike accident, and one in 10,000 as a pedestrian or in a car. In fact, the risk is the same as that of being struck by lightning."

\section{Statement 2}

"New Zealand's annual road toll is currently about 400 a year. At that rate, over 80 years 32,000 people will be killed. For a population of about 4 million, this means that there a chance of about one in 100 over 80 years that a person could be killed on the road - a risk people seem to accept.

However, in the past 80 years fewer than 500 people have been killed in NZ earthquakes - 258 in the 1931 Napier and 172 in Christchurch. Thus the annual fatality rate due to earthquakes lies at about 5 people per year. This means that over 80 years and a population of 4 million there is a chance of 1 in 10,000 of dying due to an earthauake."

Do the issues raised in these articles matter to you?

\begin{tabular}{|l|l|l|l|l|l|l|}
\hline $\begin{array}{l}\text { Not at all } \\
1\end{array}$ & 2 & 3 & 4 & 5 & 6 & 7 \\
\hline
\end{tabular}

\section{$\underline{\text { Any comments }}$}




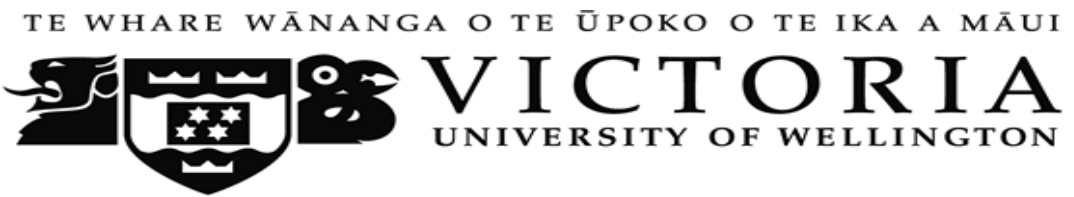

\section{Earthquakes Questionnaire}

The following statements are taken from actual newspaper articles following the Christchurch earthquakes. These statements may say exactly the same thing or slightly different things. Please read them carefully and then answer the questions on the next page.

"My workplace was on Cashel Street on the same block as the CTV building and within the dropzone of the Grand Chancellor. We are now working out of a house in Hornby which is not quite so office-like and all my favourite food places are gone. That's the worst of it for me as I never lost power or sewerage.

We had to move in with my wife's parents for a while, which allowed us to save up a deposit and we have just bought our first house. I work as a network engineer so we were very busy in the days and weeks after the quakes even with no infrastructure of our own, as it was all trapped in our building.

During the last two years we have all been forced to change priorities in the way that we work, causing our team to be more focused and streamlined so our clients get better results in less time with better solutions - it's win-win. We all slow down at road works knowing that the road is likely almost a 4WD track wherever they occur. Most of the good food places have reopened elsewhere."

Do the issues raised in these articles matter to you?

\begin{tabular}{|l|l|l|l|l|l|l|}
\hline $\begin{array}{l}\text { Not at all } \\
1\end{array}$ & 2 & 3 & 4 & 5 & 6 & 7 \\
\hline
\end{tabular}

\section{$\underline{\text { Any comments }}$}

\section{Please turn over the page and answer the following questions.}




\section{Earthquake Risk}

1.1 How likely are you or your household to be affected by a major earthquake? Please give your rating on scale from 1 to 7 , where $1=$ Extremely low probability and $7=$ Extremely high probability.

\begin{tabular}{|l|l|l|l|l|l|l|}
\hline $\begin{array}{l}\text { Extremely low } \\
\text { probability } \\
1\end{array}$ & 2 & 3 & $\begin{array}{l}\text { Medium } \\
4\end{array}$ & 5 & 6 & $\begin{array}{l}\text { Extremely } \\
\text { high } \\
\text { probability } \\
7\end{array}$ \\
\hline
\end{tabular}

\section{Paying for Preparation}

\subsection{Tax and rate allocations:}

How much would you be willing to pay in additional tax and/or rates per month, if any, for the purpose of strengthening earthquake prone public buildings?

Please circle the number closest to what you would be willing to pay in tax.

\begin{tabular}{|l|l|l|l|l|l|l|l|l|l|l|l|}
\hline$\$ 0$ & $\$ 10$ & $\$ 20$ & $\$ 30$ & $\$ 40$ & $\$ 50$ & $\$ 60$ & $\$ 70$ & $\$ 80$ & $\$ 90$ & $\$ 100$ & $\begin{array}{l}\text { Over } \\
\$ 100\end{array}$ \\
\hline
\end{tabular}

\subsection{Earthquake legislation}

There are 15,000 to 25,000 earthquake prone buildings across NZ. New legislation has been proposed by the government to require that building inspections of commercial, multilevel apartments and public buildings (not private homes) must be completed within 5 years. Owners of earthquake prone buildings will then have 10 years to bring the buildings up to at least $34 \%$ of current code. Heritage buildings can receive a 10 year extension to this time frame.

Do you think the proposed legislation is not firm enough, about right or too firm?

\begin{tabular}{|l|l|l|l|l|l|l|}
\hline $\begin{array}{l}\text { Not firm } \\
\text { enough } \\
1\end{array}$ & 2 & 3 & $\begin{array}{l}\text { About right } \\
4\end{array}$ & 5 & 6 & $\begin{array}{l}\text { Too firm } \\
\text { ( }\end{array}$ \\
\hline
\end{tabular}

2.3 Who should pay - Who do you think should pay for strengthening earthquake prone public and commercial buildings?

a. New Zealand Government

\begin{tabular}{|l|l|l|l|l|l|l|}
\hline $\begin{array}{l}\text { None of the } \\
\text { cost } \\
1\end{array}$ & 2 & 3 & 4 & 5 & 6 & $\begin{array}{l}\text { All of the } \\
\text { cost } \\
7\end{array}$ \\
\hline
\end{tabular}

b. Local Councils (e.g. Wellington city council)

\begin{tabular}{|l|l|l|l|l|l|l|}
\hline $\begin{array}{l}\text { None of the } \\
\text { cost } \\
1\end{array}$ & 2 & 3 & 4 & 5 & 6 & $\begin{array}{l}\text { All of the } \\
\text { cost } \\
7\end{array}$ \\
\hline
\end{tabular}

c. Private Owners

\begin{tabular}{|l|l|l|l|l|l|l|}
\hline $\begin{array}{l}\text { None of the } \\
\text { cost }\end{array}$ & 2 & 3 & 4 & 5 & 6 & $\begin{array}{l}\text { All of the } \\
\text { cost }\end{array}$ \\
\hline
\end{tabular}




\begin{tabular}{|l|l|l|l|l|l|l|}
\hline 1 & & & & & & 7 \\
\hline
\end{tabular}

3.1 Controllability: To what extent can people, by personal action, reduce harm from strong earthquakes?

\begin{tabular}{|l|l|l|l|l|l|l|}
\hline $\begin{array}{l}\text { Uncontrollable } \\
1\end{array}$ & 2 & 3 & 4 & 5 & 6 & 7 \\
\hline
\end{tabular}

3.2 Preventability: How likely is it that something can be done to prevent deaths from strong earthquakes?

\begin{tabular}{|l|l|l|l|l|l|l|}
\hline $\begin{array}{l}\text { Highly } \\
\text { Unlikely } \\
1\end{array}$ & 2 & 3 & 4 & 5 & 6 & $\begin{array}{l}\text { Highly } \\
\text { Likely } \\
7\end{array}$ \\
\hline
\end{tabular}




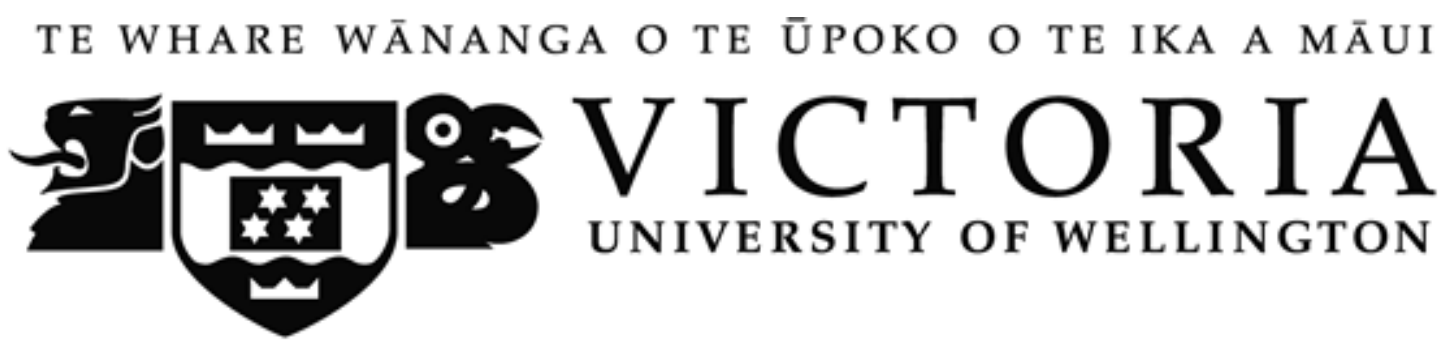

Thank you for participating in this experiment.

This study examines how people perceive the risks of earthquakes and other hazards and aims to understand how risk tolerant people are of the different hazards.

Research has shown that people have different levels of risk tolerance and desire different amounts of risk mitigation/ regulation depending on how they perceive the risks of different hazards.

Risk perception may also be influenced by media messages and the way they describe the cost and benefits of mitigating risks, such as damage from earthquakes. We presented 3 messages to 3 groups of participants. The first supports the idea that the benefits of strengthening buildings outweigh the costs whereas the second suggests that strengthening all buildings is an overreaction that comes at a cost that is too high. The third message acted as a control condition.

Knowing how people perceive different hazards can inform policy makers about how citizens of an earthquake prone region make decisions about the costs and benefits of risk mitigation and whether they are supportive of new legislation around earthquake strengthening buildings.

If you wish to receive further information, please contact Liv Henrich on henricliv@myvuw.ac.nz.

Thank you again for participating in this research.

Liv Henrich

Masters Student

Email:henricliv@myvuw.ac.nz
John McClure

\section{Professor}

John.mcclure@vuw.ac.nz

+64 (4) 463-6047 
